\author{
SERIES "THORACIC IMAGING" \\ Edited by P.A. Gevenois, A. Bankier and Y. Sibille \\ Number 4 in this Series
}

\title{
Small airways diseases: detection and insights with computed tomography
}

\author{
D.M. Hansell
}

Small airways diseases: detection and insights with computed tomography. D.M. Hansell. C) ERS Journals Ltd 2001.

ABSTRACT: Diseases affecting the small airways are difficult to detect by traditional diagnostic tests. Widespread involvement is needed before symptoms and abnormalities on pulmonary function testing or chest radiography become apparent. Obstruction of the bronchioles may be detected indirectly by computed tomography (CT) because regional under-ventilation results in reduced perfusion which in turn is shown as a mosaic attenuation pattern of the lung parenchyma. When there is inflammation of the bronchioles with accompanying exudate, the airways may become directly visible on CT, for example in cases of diffuse panbronchiolitis.

Quantification of the various morphological features of small airways disease is possible from CT images and this increased precision has aided investigations of structure/function relationships.

An understanding of the pathology and microscopic distribution of disease in relation to the airways allows some prediction of the likely computed tomography appearances in this wide spectrum of conditions, and thus helps to refine the differential diagnosis. Eur Respir J 2001; 17: 1294-1313.

National Heart and Lung Institute and Division of Investigative Science, Imperial College School of Medicine, London and Department of Radiology, Royal Brompton Hospital, London, UK.

Correspondence: D.M. Hansell, Dept of Radiology, Royal Brompton Hospital, Sydney Street, London SW3 6NP, UK.

Fax: 442073518098

Keywords: Computed tomography obliterative bronchiolitis small airways disease

Received: September 92000

Accepted after revision January 12001

The detection of various forms of small airways disease has undergone a renaissance as a result of increased understanding of the high-resolution computed tomography (HRCT) appearances of the various pathological subtypes of small airways disease. Investigation of small airways dysfunction, without reference to the state of the more proximal or distal airways, characterized much of the early pathophysiological work on small airways disease. While conceptually convenient, the reality of anatomical continuity between the small and large airways, and the presence of coexisting parenchymal abnormalities in many diseases, has been starkly revealed in the detailed images of HRCT. The known spatial resolution limits of HRCT would suggest that attempts to image the normal small airways (arbitrarily considered to be those with an internal diameter of $\leq 2 \mathrm{~mm}$ ) would appear to be, at first sight, a futile enterprise. It is in the diseased state that HRCT draws the veil aside. Abnormalities on HRCT that reflect small airways disease can be broadly categorized into indirect and direct signs: widespread scarring and obliteration of the bronchioles results in the indirect sign of patchy density differences of the lung parenchyma, representing areas of under-ventilated and under-perfused lung (the so-called mosaic attenuation pattern). By contrast, considerable thickening of the bronchiolar walls by inflammatory infiltrate and/or luminal and surrounding exudate render the affected small airways directly visible. This article concentrates on the HRCT imaging of the "purer" forms of bronchiolar disease, while acknowledging that there is a "small airways" component, to a greater or lesser extent, in the heterogeneous totality of chronic obstructive pulmonary disease (COPD). Some of the principles and observations contained in this review are applicable to the commoner, if less tangible, entity of COPD. Although primacy is given to HRCT in this review, some of the signs and functional correlations discussed may well be applicable to other forms of imaging, in particular the rapidly developing technique of hyperpolarized gas magnetic resonance imaging (MRI) of the lungs [1].

\section{Pathological background and classification}

Inflammation of the bronchioles with or without subsequent scarring and bronchiolar obliteration is a very common lesion in the lungs [2] and pathological

Previous articles in this series: No. 1: Ghaye B, Dondelinger RF. Imaging guided thoracic interventions. Eur Respir J 2001 ; 17: $507-528$. No. 2: Vansteenkiste JF, Stroobants SG. The role of positron emission tomography with ${ }^{18}$ F-fluoro-2-deoxy-D-glucose in respiratory oncology. Eur Respir J 2001; 17: 802 -820. No. 3: Kauczor HU, Chen XJ, van Beek EJR, Schreiber WG. Pulmonary ventilation imaged by magnetic resonance: at the doorstep of clinical application. Eur Respir J 2001; 17: 1008 - 1023. 
studies have repeatedly emphasized the frequent bronchiolar involvement in diverse diffuse lung diseases. Because of the wide variety of conditions which are characterized by an element of bronchiolar damage, the term "small airways disease" has much to recommend it; from the imaging point of view, the term does not attempt to define the exact size of the airways included in this generic term, but it can usefully be taken to include all airways below the resolution of HRCT in the normal state.

The specific and classical term obliterative bronchiolitis (synonym: bronchiolitis obliterans) has, until recently, been the subject of confusion, primarily because of its use in the context of bronchiolitis obliterans organizing pneumonia (BOOP). The clinicopathological entity of BOOP, more usefully termed cryptogenic organizing pneumonia (COP) [3], should be regarded as quite distinct from obliterative bronchiolitis and it has been suggested that the bronchiolitis obliterans part of BOOP should be discarded altogether [4]. Given its distinctive features, BOOP/ organizing pneumonia is not considered further in this review.

The various conditions included within the term small airways diseases are usually classified into pathological subtypes or by less precise clinical criteria (usually by presumed cause or association). The latter approach has become increasingly unsatisfactory because of the increasing number of new causes and associations reported in the literature. While pathologists categorize small airways diseases according to their histopathological subtypes [5], the difficulty with this traditional approach is that there are not always obvious clinical or imaging correlates with these pathological subtypes. One of the more comprehensive histopathological schemes, described by MYERS and Colby [6] is shown in table 1. Many other schemes are loosely based on the classification of Myers and Colby [6], for example an abbreviated version by WORTHY and MüLLER [7] includes the following five histopathological entities: 1) cellular bronchiolitis; 2) panbronchiolitis; 3) respiratory bronchiolitis;

Table 1.-Classification of small airways disease by pathological features

Constrictive bronchiolitis

Obliterative bronchiolitis

Bronchiolitis obliterans

Cryptogenic organizing pneumonia

Bronchiolitis obliterans organizing pneumonia

Proliferative bronchiolitis

Acute bronchiolitis Infectious bronchiolitis

Small airways disease Adult bronchiolitis

Respiratory bronchiolitis

Smoker's bronchiolitis

Respiratory bronchiolitis-associated interstitial lung disease

Mineral dust airways disease

Early pneumoconiosis

Follicular bronchiolitis

Diffuse panbronchiolitis

Adapted from ref [6]
4) constrictive bronchiolitis; and 5) bronchiolitis obliterans with intraluminal polyps. Whereas HwANG et al. [8] categorize small airways disease as follows: 1) infectious bronchiolitis; 2) constrictive bronchiolitis; 3) proliferative bronchiolitis (i.e. BOOP); 4) respiratory bronchiolitis; 5) diffuse panbronchiolitis; and 6) mineral dust-induced bronchiolitis.

A simpler approach relies on the fundamental difference between the indirect HRCT signs of constrictive bronchiolitis and the direct visualization of the small airways on HRCT in exudative forms of bronchiolitis (typified by diffuse panbronchiolitis). These two basic HRCT patterns of small airways disease account for the majority encountered in clinical practice. Other miscellaneous forms of small airways disease with more or less distinctive pathological and imaging features, if not clinical presentations, are dealt with separately.

\section{High-resolution computed tomographic technique}

Standard HRCT technique is satisfactory for demonstrating the features of various obstructive lung diseases, particularly in advanced disease. However, some modifications are needed to enhance the sometimes subtle signs of small airways disease. The two fundamental forms of small airways disease, namely constrictive (obliterative) bronchiolitis and, at the other end of the pathological/imaging spectrum, diffuse panbronchiolitis make different demands on the technique; for the optimal imaging of patients with constrictive bronchiolitis, appropriate contrast resolution is needed to demonstrate regional density differences (mosaic attenuation pattern), whereas the imaging of patients diffuse panbronchiolitis necessitates adequate spatial resolution to depict the characteristic small branching structures (tree-in-bud pattern).

Despite the relatively few technical parameters that can be altered when performing a HRCT examination, the final appearance of the images of the lungs obtained on different computed tomography (CT) scanners, even with the use of identical window settings (the controls that determine the contrast and depth of the grey scale of the CT image), can be remarkably different. Such differences may be problematic, particularly in the context of the confident identification of a mosaic attenuation pattern or assessment of the degree of wall thickening of the macroscopic bronchi.

Window settings have a marked effect on the apparent size of structures [9] and in the context of diseases of the airways, the most obvious effect of inappropriate window settings is on the thickness of bronchial walls. Narrowing the window settings will increase apparent bronchial wall thickness and at the same time reduce the apparent internal bronchial diameter. No absolute window settings can be recommended because of variation between CT machines and individuals preferences, however for diagnostic purposes consistent window settings from patient to patient are advisable and a window level of $-400--950$ Hounsfield Units (HU) and a width of 1,000-1,600 HU have been widely recommended 
[10-12]. In a study that correlated thin-section CT with planimetric measurements of inflation-fixed lungs [13], it has been shown that wider latitude is possible; specifically, for the accurate estimation of bronchial wall thickness the authors suggest that, irrespective of the chosen window width, the window centre should be $-250--700 \mathrm{HU}$, and that within this range bronchial wall thickness is not appreciably affected (window width should be $>1,000 \mathrm{HU}$, a narrower window width will cause a spurious appearance of bronchial wall thickening). A survey of thoracic radiologists indicates that for the evaluation of the lung parenchyma, the majority use a window level of $-600 \mathrm{HU}$ and a window width of $1,500 \mathrm{HU}$ [14].

A typical HRCT protocol used in clinical practice would simply be thin $(1-2 \mathrm{~mm})$ collimation sections at $10 \mathrm{~mm}$ interval from lung apices to the costophrenic angles with the patient breath-holding at full inspiration, in a supine position. Normal lung parenchyma increases in attenuation on expiration (fig. 1). Areas of air-trapping caused by small airways disease are seen as regional inhomogeneity, i.e. areas that remain relatively lucent (black) interspersed with areas of normal higher density lung (fig. 2).
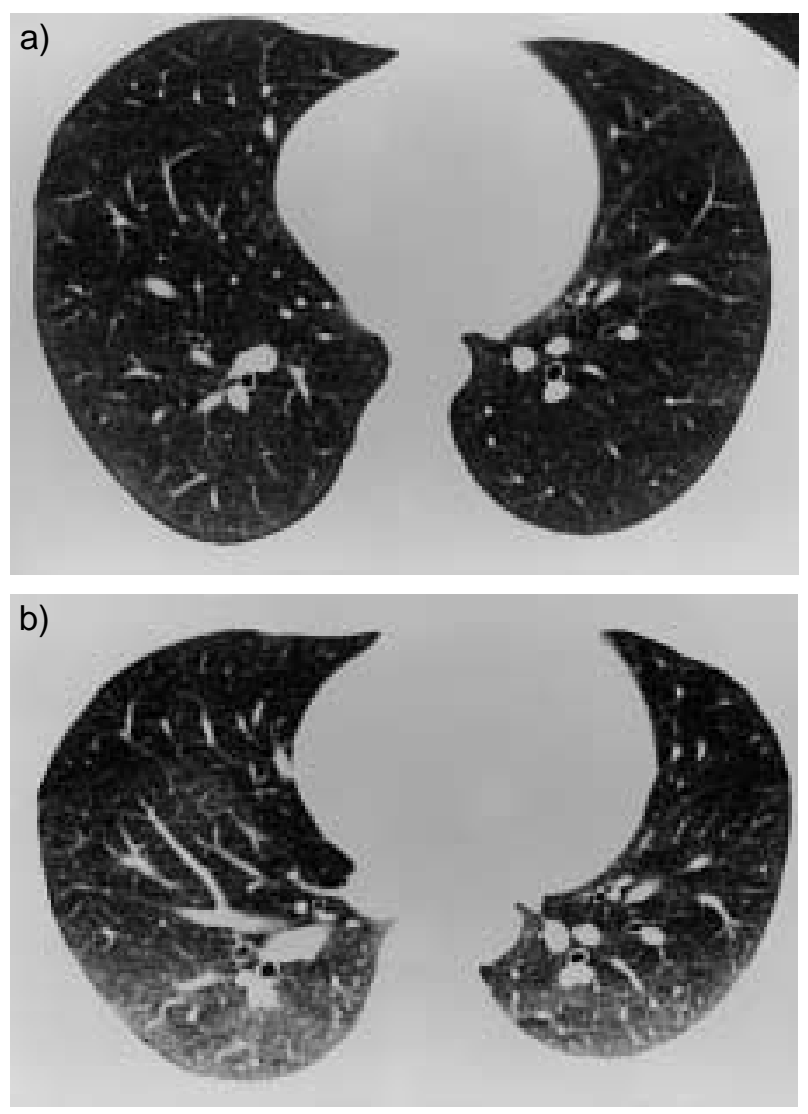

Fig. 1. - a) Normal appearances of the lung parenchyma on thinsection computed tomography in a patient breath-holding at full inspiration. Apart from the gradual increase in density of the lung parenchyma in the dependent to nondependent axis, the density of the lung parenchyma is homogeneous. b) At approximately the same anatomical level breath-holding at near residual volume (end-expiration), the density gradient is emphasized, but otherwise the attenuation of the lungs remains relatively uniform.
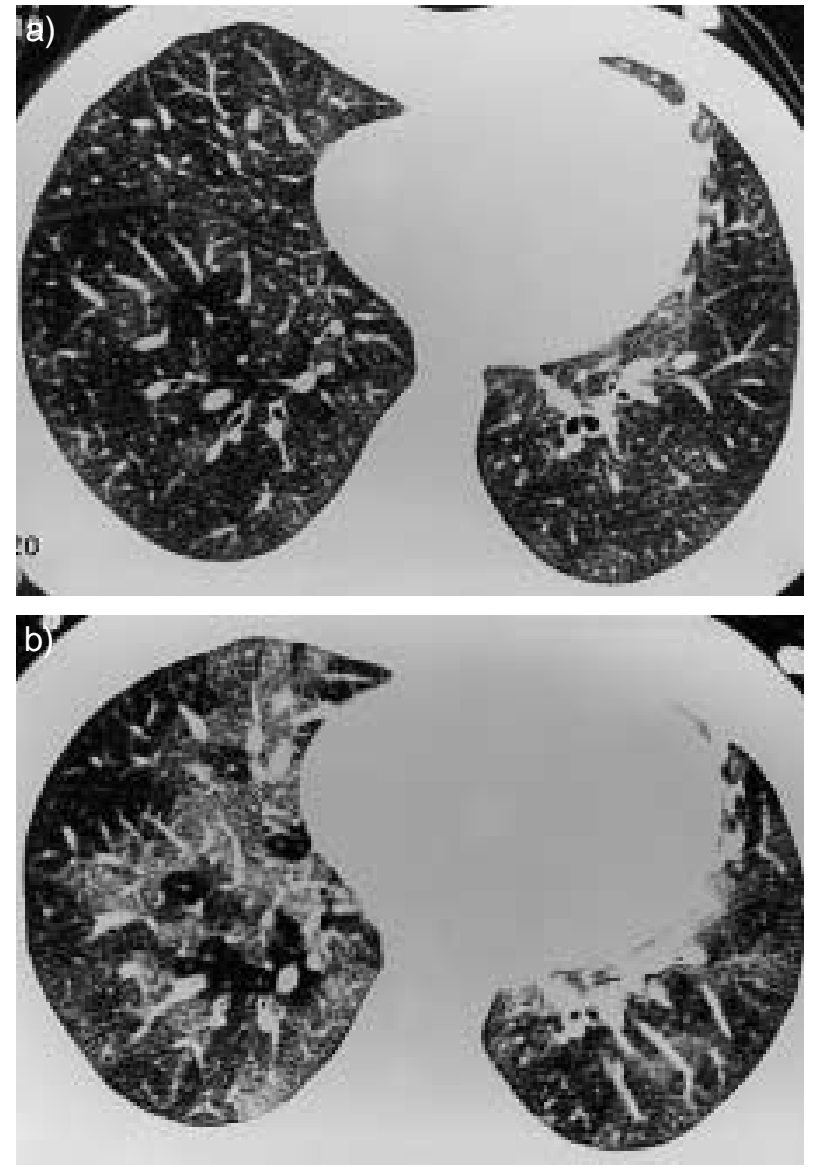

Fig. 2. - Post bone marrow transplant patient. a) On this inspiratory high-resolution computed tomography section, there are patchy density differences throughout the lung parenchyma. Within areas of decreased attenuation (blacker lung) the pulmonary vessels are of relatively decreased calibre. b) At endexpiration, the regional inhomogeneity of the density of the lung parenchyma is much more conspicuous.

This important sign of enhancement of the mosaic attenuation pattern on CT sections obtained at endexpiration (usually limited to approximately six sections taken between the aortic arch and right hemidiaphragm) has led some workers to suggest that they should be acquired routinely, irrespective of the findings on the standard inspiratory HRCT sections $[15,16]$. Whether expiratory CT sections need to be obtained in all cases of suspected small airways disease is questionable. However, there is no doubt that presymptomatic air-trapping in, for example, cigarette smokers may be detectable on expiratory CT in the face of normal inspiratory CT images [17]. Furthermore, it is often reassuring to have the sometimes subtle mosaic pattern emphasized on additional expiratory sections.

Obtaining end-expiratory CT images is not always straightforward and a few patients are unable to comply, despite coaching by an experienced technologist, with the request to "breathe right out and hold it". Determining the state of inflation of the lungs from the appearances of the inspiratory and expiratory CT scans is largely subjective, but invagination 


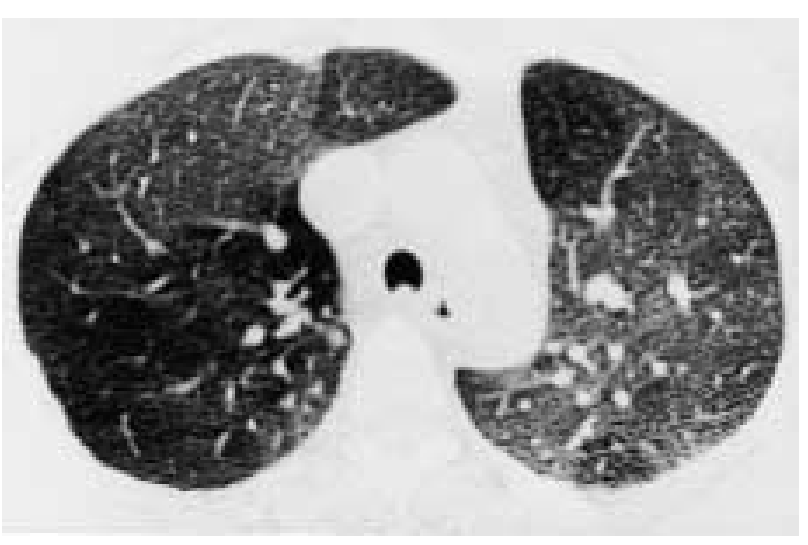

Fig. 3. - End-expiratory computed tomography, as judged by invagination of the posterior membrane of the trachea (compare with fig. 4) emphasizing the mosaic attenuation pattern in a patient with postviral constrictive obliterative bronchiolitis.

of the posterior membrane of the trachea on the expiratory CT scan implies a satisfactory effort by the patient (fig. 3); the normal decrease in cross-sectional area of the lungs, at the level of the carina, by $\sim 55 \%$ at end-expiration is, in practice, less easy to gauge [18]. Despite the theoretical attractions of spirometricallygated CT, in which images are obtained at predetermined levels of lung inflation [19-21], relatively few clinical studies have made use of this method. For patients who are unable to reliably suspend respiration, specifically at end-expiration, scanning in a decubitus position has been suggested [22]; in this position the dependent lung is relatively restricted and so mimics the state of the lungs at end-expiration.

There are other manoeuvres that may enhance the appearance of air-trapping [23]. Sections obtained in quick succession during forced expiration, for example at a rate of two per second at a given level, may show areas of air-trapping that are inconspicuous or absent on sections obtained more conventionally at end-expiration [24]; the physiological reasons for the increased conspicuity of air-trapping on dynamic CT examinations are not fully understood [25] but may reflect the "pendelluft" phenomenon whereby partially obstructed lung empties more slowly than normal lung during rapid expiration, so emphasizing attenuation differences [26]. A recent study that compared low-dose dynamic expiratory $\mathrm{CT}$ with the more conventional end-expiratory $\mathrm{CT}$ technique demonstrated that the density changes were significantly greater with the dynamic technique [27], but artefact inherent in the low-dose dynamic method may be problematic. Nonetheless, this study provides further support for the concept that CT data obtained during, rather than following, expiration is the most sensitive mode for detecting air-trapping on CT.

The density differences that characterize the mosaic attenuation pattern on HRCT, on either inspiratory or expiratory images, may be very subtle and close to the limit of visual detection. Altering window settings may increase the conspicuity of a mosaic pattern but the subjective manipulation of window settings will spuriously affect the apparent extent of abnormal versus normal lung (fig. 4). Simple image processing of

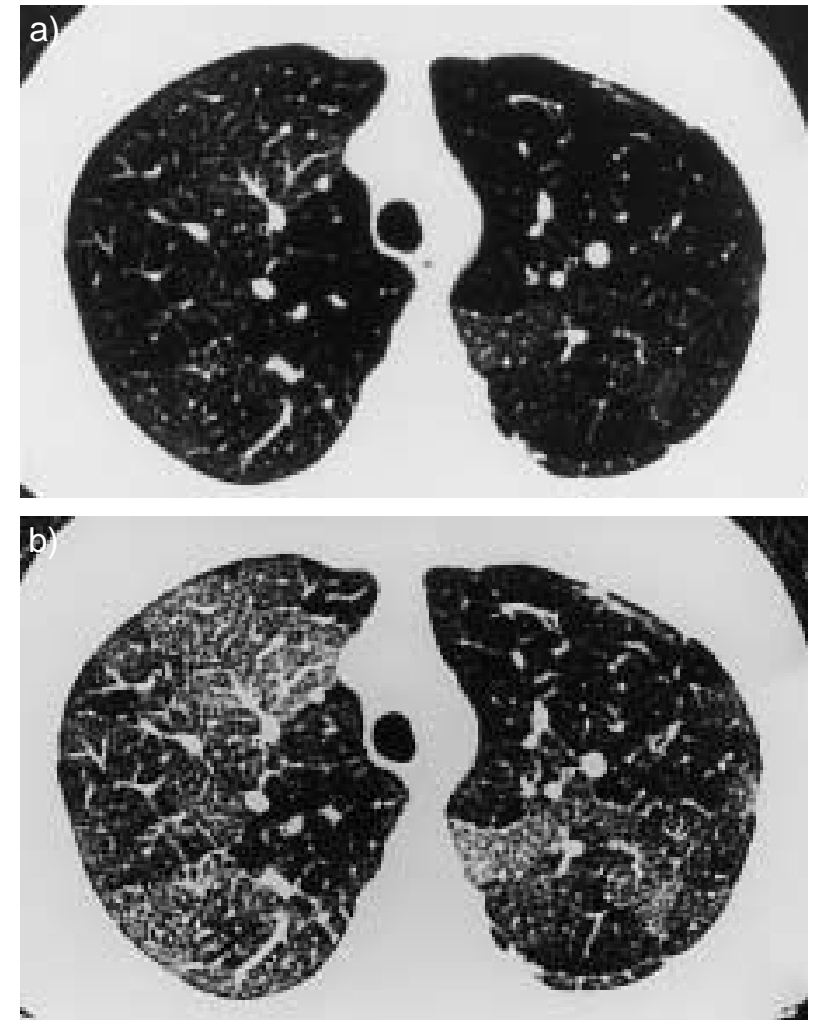

Fig. 4. - Patient with rheumatoid arthritis associated constrictive obliterative bronchiolitis. a) Inspiratory high-resolution computed tomography section through the upper lobes using conventional window settings (centre: -600, width: 1,400 HU); the density differences in the lung parenchyma are subtle. b) By narrowing the window settings, the contrast between regions of lung of differing attenuation is emphasized, and the apparent extents are altered.

CT data can be used to improve detection and decrease observer variation. Spiral CT can be used to acquire a "slab" of anatomically contiguous thin-sections (for example, a $5 \mathrm{~mm}$ slab consisting of five adjacent $1 \mathrm{~mm}$ sections); a simple image processing algorithm is applied whereby only the lowest attenuation value of the five adjacent pixels is projected on the final image, producing a so-called "minimum intensity projection (MinIP) image". This technique improves the detection of subtle areas of low attenuation, encountered in small airways disease and emphysema [28, 29]. There is no doubt that MinIP and similar postprocessing of HRCT images improves the conspicuity of the regional inhomogeneity of the lung parenchyma caused by small airways diseases (fig. 5) $[30,31]$, and these techniques are useful in the investigation of structure/function relationships (see later) but they are not routinely used in clinical practice.

While much of the current (and probably future) work has relied on HRCT images for disease quantification, the volumetric acquisition of CT data using spiral and multidector CT holds a promise for specific applications. The basis of spiral CT scanning is continuous movement of the patient through the CT gantry while the x-ray tube and detector rotate around the long axis of the patient. In this way, there is fast, 

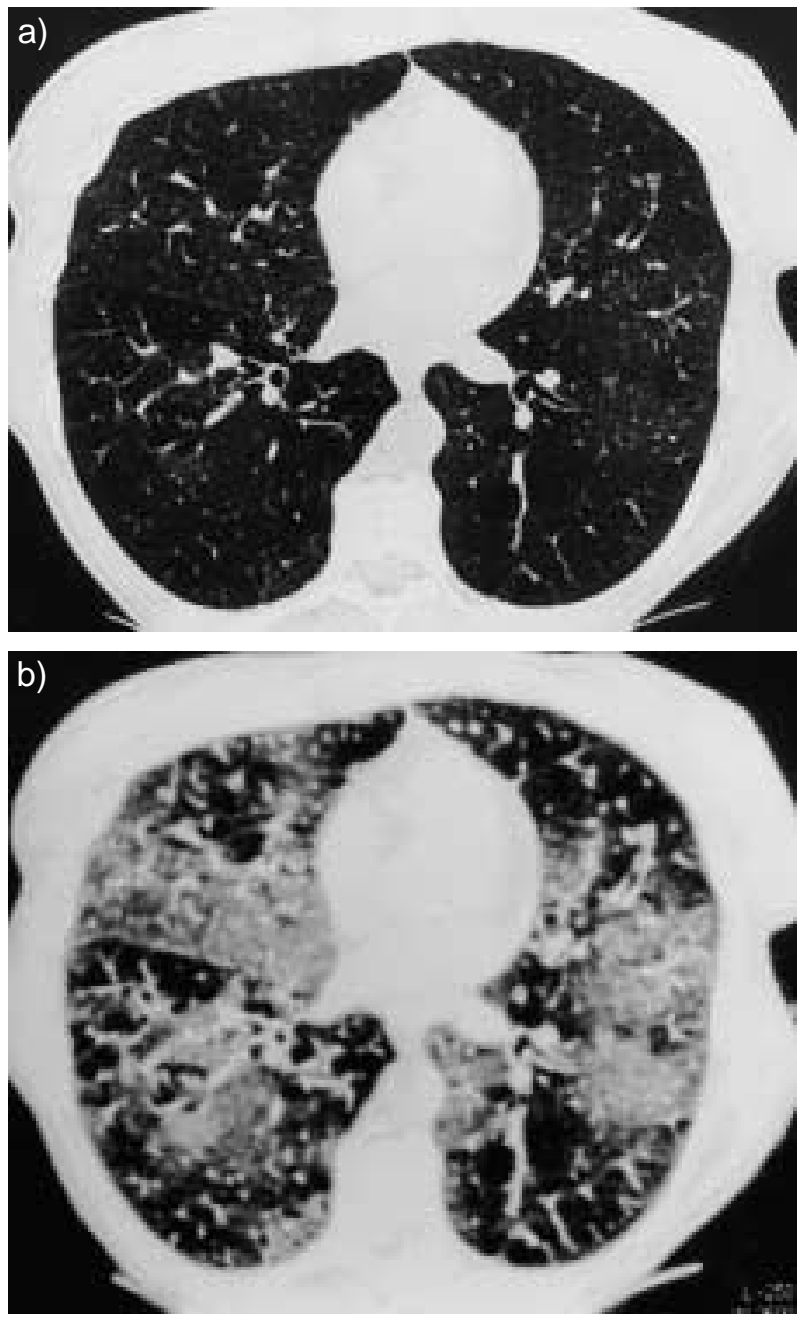

Fig. 5. - Patient with constrictive obliterative bronchiolitis. a) Subtle regional differences in the density of the lung parenchyma on an inspiratory high-resolution computed tomography section through the lower lobes. On lower sections there was mild cylindrical bronchiectasis. b) A minimum intensity projection image grossly exaggerates the contrast between normal and abnormal lung (at the same time rendering other diagnostic features, such as bronchial abnormalities, less visible).

continuous and complete acquisition of data of the whole thorax. For clinical diagnostic purposes, the volumetric data is reconstructed into "conventional" cross-sectional images and in this respect, the full potential of novel analysis and presentation of volumetric data has yet to be realized [32].

\section{Constrictive (obliterative) bronchiolitis}

Constrictive bronchiolitis is associated with numerous predisposing conditions or causative agents and the most frequently encountered are shown in table 2 .

Viral lower respiratory tract infections are a common cause of constrictive bronchiolitis, particularly in children [33, 34]. Nonviral agents are much less commonly implicated, although Mycoplasma pneumoniae [35] is an especially potent cause of constrictive bronchiolitis because of its predilection
Table 2.-Some causes and associations of constrictive (obliterative) bronchiolitis

Postinfectious (ususlly viral)

Adenovirus

Respiratory syncytial virus

Influenza

Mycoplasma pneumoniae

Inhalational injury

Nitrogen dioxide (silo-filler's disease)

Sulfur dioxide

Ammonia

Phosgene

Hot gases

Connective tissue disorders

Rheumatoid arthritis

Sjögren's syndrome

(Others very rarely)

Transplant recipients

Bone marrow transplant

Heart-lung or lung transplant

Drugs

Penicillamine

Lomustine

Other conditions

Inflammatory bowel diseases

Bronchiectasis, including cystic fibrosis

Hypersensitivity pneumonitis

Microcarcinoid tumourlets

Sauropus androgynus ingestion

Paraneoplastic pemphigus

Truly cryptogenic cases of constrictive bronchiolitis are exceedingly rare.

for the respiratory epithelium. There are sporadic reports in the literature suggesting that bacterial infections, for example Nocardia asteroides and Legionella pneumophila, may be responsible for an obliterative bronchiolitis [36, 37]; however, the imaging and pathology described in these reports is of an organizing pneumonia rather than constrictive bronchiolitis (highlighting the historical confusion surrounding the terminology of "bronchiolitis obliterans" and "BOOP" referred to earlier). Nevertheless, infection with $M$. pneumoniae is one of the uncommon situations in which both constrictive bronchiolitis and "proliferative" bronchiolitis (i.e. BOOP) truly coexist [38]. There is indirect evidence that in a few specific situations, bacterial colonization or infection is associated with small airways involvement; in patients with idiopathic bronchiectasis, there is a link between infection with Pseudomonas aeruginosa and the extent and severity of CT features of bronchiectasis and constrictive bronchiolitis, by comparison with nonPseudomonas infected bronchiectatic patients [39]. A similar association has been reported in patients with Mycobacterium aviumintracellulare infection, but no pre-existing lung disease, who had a high prevalence of functional and CT evidence of small airways disease compared to a control group [40] (fig. 6). The nature of such relationships ("cause versus effect") has not been established.

Repeated viral lower respiratory tract infections are common in adult life, but clinically significant constrictive bronchiolitis as a consequence is fortunately rare [41]; however, the incidental finding of focal 


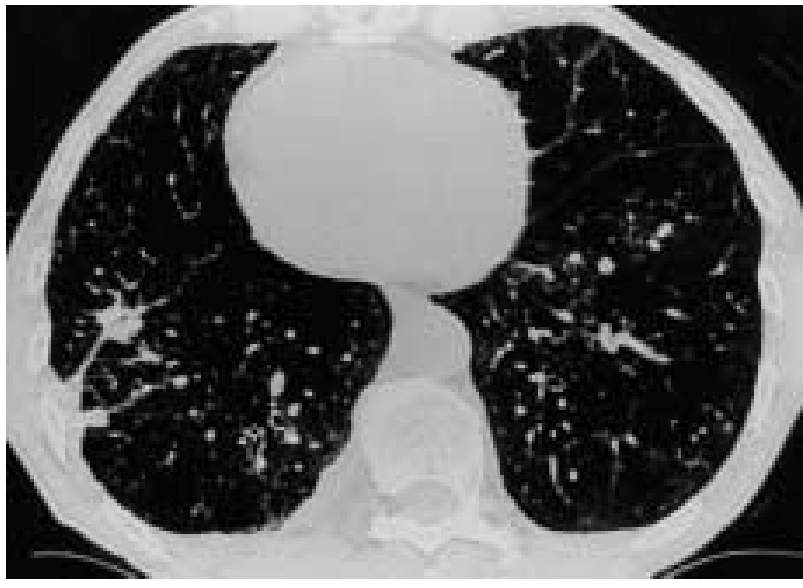

Fig. 6. - Atypical mycobacterial infection (Mycobacterium aviumintracellulare). There is generalized mild cylindrical bronchiectasis and several nodules, one of which is cavitating (right lower lobe). Elsewhere in the lungs there was a mosaic attenuation pattern consistent with coexisting small airways disease.

areas of decreased attenuation at HRCT in otherwise healthy individuals may represent the clinically silent sequel of such episodes. Swyer-James (or MacLeod's) syndrome is a particular form of constrictive bronchiolitis that occurs following an insult, usually a viral infection sustained in childhood, to the developing lung. The characteristic pathophysiological feature is that lung served by damaged airways remains inflated by collateral air drift. Further development of the lung is arrested resulting in hypoplasia of the lung tissue, including the pulmonary arteries which are reduced in both size and number. As defined in the original radiographic descriptions, the transradiancy is predominantly or exclusively unilateral. The inhomogeneous nature of lung involvement is particularly well demonstrated on CT, which shows bronchiectatic changes and bilateral features of constrictive bronchiolitis in most cases [42-45]. The key feature of air-trapping is well demonstrated on expiratory CT scans.

Constrictive bronchiolitis is a predictable consequence of the inhalation of many toxic fumes and gases which reach the small airways [46]. It has been most frequently described following nitrogen dioxide inhalation (silo-filler's disease) [47]. Epithelial injury, notably to ciliated cells, is almost invariable following exposure to any oxidant gas or hot smoke, so that bronchiectasis readily seen on CT usually accompanies this type of obliterative bronchiolitis [48]. A wide variety of inorganic dusts, including silica, asbestos, mica, talc and iron or aluminium oxides have the potential to cause small airway obliteration, but this is often overlooked because of the apparently dominant pathology of dust-induced interstitial fibrosis [49]. A problem in recognizing mineral dust-induced small airways disease is the similarity of lesions, namely mural fibrosis and pigmentation, found in both cigarette smokers and nonsmoking dust-exposed workers. However, when dust-exposed individuals are compared to matched nondust-exposed smoking control subjects, the degree of fibrosis around the terminal bronchioles is considerably greater in dustexposed individuals [50]. In the specific case of asbestos exposure, the earliest phases of asbestosinduced pulmonary damage is peribronchiolar fibrosis and this lesion can be identified on HRCT images as minute irregular centrilobular nodules [51]. Whether other CT signs of constrictive bronchiolitis, notably air-trapping on expiratory CT, occur with any frequency in inorganic dust-induced pulmonary disease has not been reported.

Among the connective tissue diseases, constrictive bronchiolitis is most strongly associated with rheumatoid arthritis [52-54]. Constrictive bronchiolitis associated with rheumatoid arthritis is often rapidly progressive with refractory airflow obstruction unresponsive to any treatment [53]. Nevertheless, minor degrees of constrictive bronchiolitis are probably present and subclinical in many patients with rheumatoid arthritis $[55,56]$. In a CT study of 84 patients, $30 \%$ showed features of bronchiectasis/bronchiolectasis, presumed to reflect small airways involvement [57]. In the context of rheumatoid arthritis, with the potential for coexisting interstitial pulmonary fibrosis, the question arises of whether abnormalities of the large airways are due to distortion by surrounding fibrosis (traction bronchiectasis) or are the epiphenomenon of small airways disease; there have been no HRCT-pathological correlative studies that have addressed this specific question. HRCT has revealed that both interstitial and airways disease frequently coexist in patients with rheumatoid arthritis (fig. 7). Pencillamine has been incriminated as a contributory causative agent. In a study of 602 patients with rheumatoid arthritis, there was a $3 \%$ prevalence of clinically apparent constrictive bronchiolitis, and cases were confined to those patients receiving penicillamine [58], nevertheless penicillamine is not a sine qua non for the development of constrictive bronchiolitis in rheumatoid arthritis patients [52]. Patients with Sjögren's syndrome may have a combination of interstitial disease (usually lymphocytic

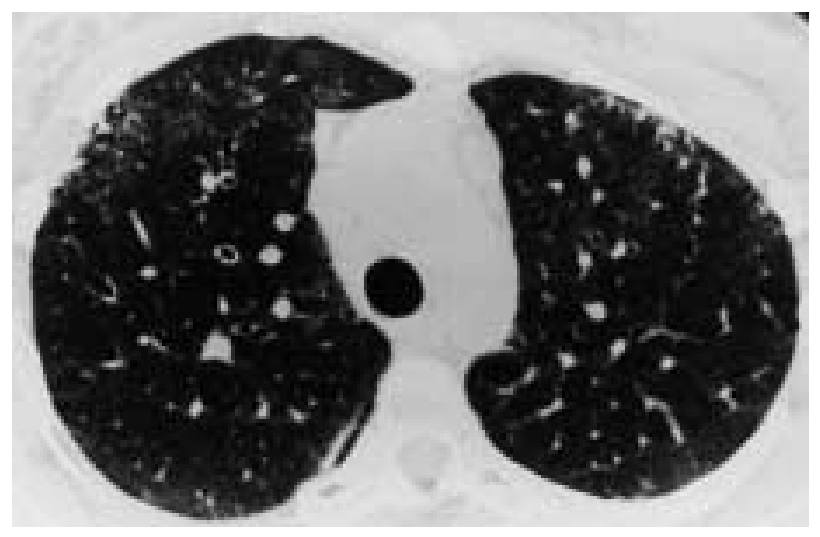

Fig. 7. - Patient with rheumatoid arthritis and mixed restrictive and obstructive pulmonary function test data. There is a peripheral reticular pattern with some dilatation of the airways within this abnormal (fibrotic) lung. In addition, the lung in the right upper lobe is of reduced attenuation and there is mild bronchial wall thickening and dilatation, reflecting the coexisting small airways disease. 
interstitial pneumonitis) and bronchiolocentric lymphocyte infiltration but, unlike rheumatoid arthritis, constrictive bronchiolitis is rarely the dominant presenting feature $[59,60]$.

Constrictive bronchiolitis is an important and frequent cause of morbidity and mortality in patients receiving heart and lung transplants [61, 62]. It occurs in up to $50 \%$ of recipients and usually manifests itself between $9-15$ months (range 60 days -5.6 yrs) after transplantation [63, 64]. It is probable that subclinical damage to small airways epithelium (secondary to acute rejection and/or cytomegalovirus (CMV) infection) occurs earlier, within the first few weeks following transplantation, and that subtle HRCT abnormalities caused by, for example, CMV infection [65] may predate the functional abnormalities of supervening small airways obliteration [66]. The contribution of imaging to the detection of acute rejection in these circumstances is limited, but the identification of areas of ground-glass opacification on HRCT within the first few months after transplantation is suggestive although nonspecific [67]. Modification of the immunosuppressive regimen may be successful in delaying the development of constrictive bronchiolitis, but relapses are common [64]. The reported sensitivity and specificity of HRCT for the diagnosis of established constrictive obliterative bronchiolitis in postlung transplant patients has been variable, largely due to differences in patient selection and the HRCT feature evaluated [66, 68, 69-72]. Early studies concentrated on bronchiectasis, rather than a mosaic attenuation pattern, as the marker of obliterative bronchiolitis [73, 74], but more recently attention has turned to the mosaic attenuation pattern on inspiratory CT and, more particularly, on expiratory CT; in one series the sensitivity of $40 \%$ and specificity of $78 \%$ increased to $80 \%$ and $94 \%$ respectively, when expiratory $\mathrm{CT}$ sections were examined [69]. In a study by LEUNG et al. [69], airtrapping on expiratory $\mathrm{CT}$ was the most sensitive sign (sensitivity $91 \%$ ) of obliterative bronchiolitis in 11 patients with transbronchial biopsy confirmation [69]. Nevertheless, there is considerable heterogeneity between series concerning which test (transbronchial biopsy, pulmonary function testing, expiratory HRCT) is the most accurate for the detection of obliterative bronchiolitis in post-transplant patients. A recent study suggests that air-trapping on expiratory CT is not as specific or sensitive as previously thought [71]; the air-trapping score in patients with biopsy proven obliterative bronchiolitis was not significantly different to biopsy negative patients with airflow limitation. However, given the patchy nature of the disease, a negative transbronchial biopsy does not necessarily preclude obliterative bronchiolitis [75] and expiratory HRCT may show evidence of obliterative bronchiolitis in some biopsy negative cases [71].

Obliterative bronchiolitis also occurs following bone marrow transplantation [63, 76, 77]. The disorder develops usually within 18 months of transplantation and is variably responsive to increased immunosuppression. At this stage, other complications (including a variety of infections, pulmonary oedema and drug toxicity) are frequent [78] and imaging characteristics are not discriminatory [63]. In general, clinically obvious obliterative bronchiolitis occurs in only a small proportion of patients following allogeneic bone marrow transplant and is usually less severe than that seen following lung transplantation [77].

Constrictive bronchiolitis is rarely truly cryptogenic [79, 80]; most cases probably have an undisclosed precipitating cause or association, such as a connective tissue disease which subsequently declares itself [81].

\section{High-resolution computed tomography of individual features of constrictive bronchiolitis}

The plain radiographic features of constrictive bronchiolitis are nonspecific, and absent in all but the most severe cases; the signs can be summarized as diminished pulmonary vasculature and over-inflation of the lungs with or without bronchial wall thickening [82-84]. These abnormalities, seen in any form of COPD, are prone to considerable observer variation.

In one of the first CT studies of constrictive bronchiolitis, 15 patients who fulfilled the criteria of TuRTON et al. [79] were examined with conventional (contiguous $10 \mathrm{~mm}$ sections) and thin-section CT (interspaced $3 \mathrm{~mm}$ sections) [85]. Chest radiographs were normal in five of 15 patients; the remaining 10 patients showed "limited vascular attenuation and hyperinflation". In 13 of 15 a pattern of "patchy irregular areas of high and low attenuation in variable proportions, accentuated in expiration" was recorded. This, and a report of two cases by EBER et al. [86], were the first reports to identify regional inhomogeneity of the density of the lung parenchyma as the key CT feature of constrictive bronchiolitis.

Subsequent descriptions have confirmed and refined the HRCT features of constrictive bronchiolitis [8, $87-90]$. The HRCT signs comprise areas of reduced density of the lungs (the patchy density differences giving rise to the term "mosaic attenuation pattern"), constriction of the pulmonary vessels within areas of decreased lung density, bronchial abnormalities, and lack of change of cross-sectional area of affected parts of the lung on scans obtained at end-expiration [44, 91]. These individual CT signs of constrictive bronchiolitis are now considered in more detail.

\section{Areas of decreased density of the lung parenchyma}

Regions of decreased attenuation ("black lung") usually have poorly defined margins (fig. 8), but sometimes have a sharp geographical outline (representing a collection of affected secondary pulmonary lobules) (fig. 9). The relatively higher attenuation regions of lung represent relatively increased perfusion of the normally ventilated lung. When severe, the lung may be of homogeneously decreased attenuation (so that the patchy density difference, or mosaic pattern, is lost) (fig. 10). 


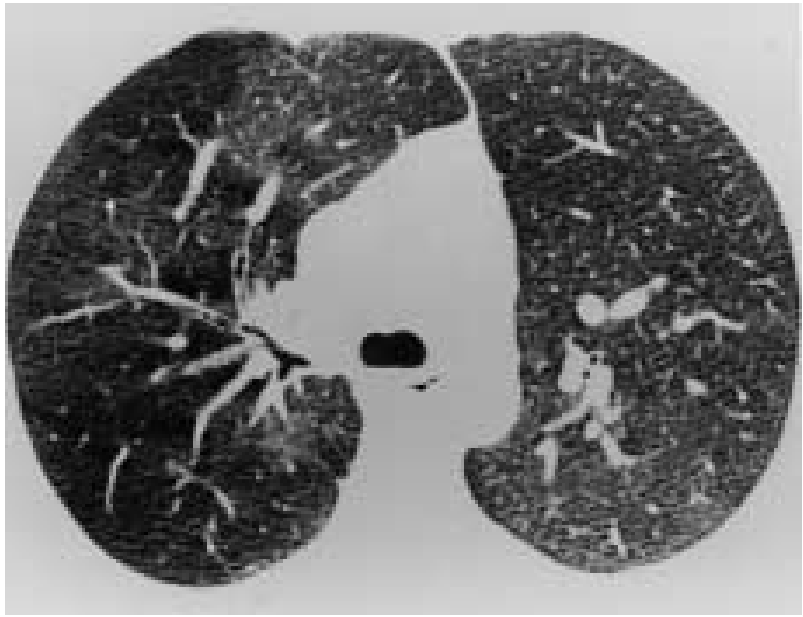

Fig. 8. - Postviral constrictive obliterative bronchiolitis. Asymmetric lung involvement; the margins between the abnormal (decreased density) lung and the relatively normal lung are ill defined (by comparison with example in fig. 9).

Reduction in calibre of the macroscopic pulmonary vessels

In the areas of decreased attenuation, pulmonary perfusion is reduced. In acute bronchiolar obstruction this represents physiological reflex of hypoxic vasoconstriction [92] but in the chronic state there is vascular remodelling and the reduced perfusion becomes irreversible. In some instances, the inflammatory process that causes bronchiolar scarring may synchronously affect the adjacent pulmonary artery, thus leading to vascular obliteration. Although the vessels within areas of decreased attenuation on HRCT may be of markedly reduced calibre they are not distorted.

\section{Abnormalities of the macroscopic airways}

The severity of bronchial dilatation and wall thickening is highly variable from one case to another;

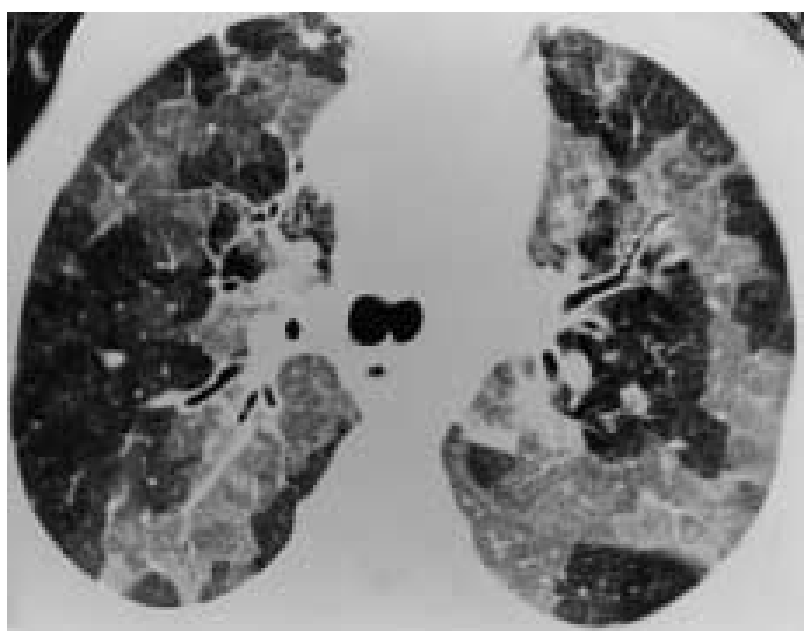

Fig. 9. - Postlung transplant obliterative bronchiolitis. In this case the affected lung is apparently made up of a patchwork of secondary pulmonary lobules, giving a geographical outline to the interface between normal and abnormal lung.

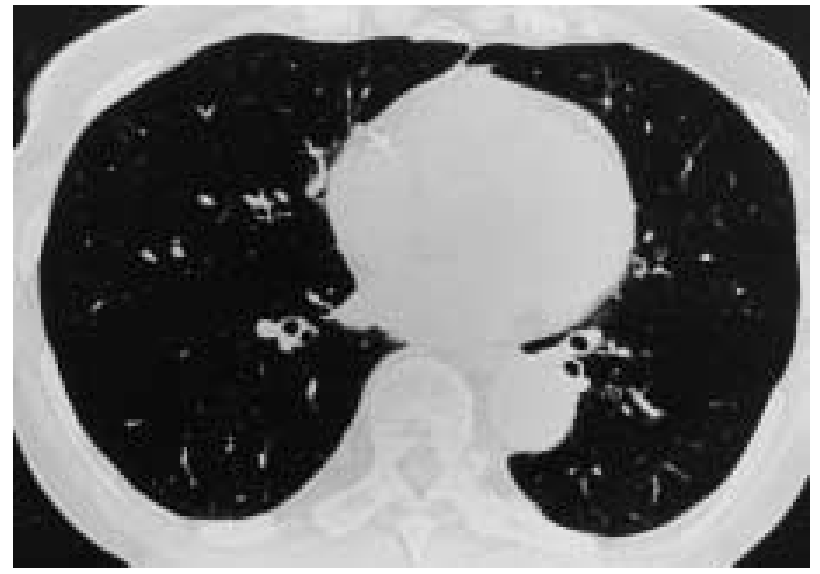

Fig. 10. - Advanced constrictive obliterative bronchiolitis (rheumatoid arthritis patient). There is a uniform decrease in attenuation of the lung parenchyma, such that no mosaic attenuation pattern is present (the appearance of the lungs was identical at end-expiration, with virtually no change in cross-sectional area of the lungs). There are mild abnormalities of the macroscopic bronchi. Such severe disease may be difficult to distinguish from panacinar emphysema.

in immunologically mediated constrictive bronchiolitis (e.g. post-transplant or rheumatoid arthritis associated), marked dilatation of the bronchi is a frequent finding [57, 68]. Some degree of bronchial thickening and dilatation is the rule in most patients with constrictive bronchiolitis [89].

\section{Air-trapping at expiratory computed tomography}

The regional inhomogeneity of the lung density is accentuated on sections obtained at end-, or during, expiration. Areas of decreased attenuation, not visible on inspiratory CT sections, may be detectable on endexpiratory CT sections [16, 17, 23, 93]. The crosssectional area of the affected parts of the lung do not decrease in size on expiratory CT [91]. Expiratory CT may also be helpful in differentiating between the three main causes of a mosaic pattern (infiltrative lung disease, small airways disease, and occlusive pulmonary vascular disease) which may be problematic on inspiratory CT $[15,94]$. An important caveat is that in patients with widespread small airways disease, endexpiratory CT sections may appear virtually identical to the standard inspiratory CT sections, simply because of the severity of the air-trapping (i.e. there is no mosaic pattern or change in cross-sectional area of the lungs) (fig. 10).

\section{Accuracy of high-resolution computed tomography signs and interpretive pitfalls}

The individual HRCT features of constrictive bronchiolitis are not, in isolation, specific for that disease and may be encountered in other COPDs. Conversely, the sensitivity of the individual, or combined, HRCT signs of constrictive bronchiolitis cannot be easily extracted from the current literature. 
However, in the context of a known cause or association of constrictive bronchiolitis, an HRCT examination showing the concatenation of mosaicism, bronchial abnormalities and air-trapping on expiratory images can be regarded as diagnostic. The frequency with which "significant" obliteration of the small airways occurs without accompanying abnormalities on HRCT is unknown, and given the lack of a reliable in vivo gold standard, this question remains open. Furthermore, there are circumstances in which the discrimination between constrictive bronchiolitis and other obstructive pulmonary diseases, particularly in advanced disease, can be difficult.

In considering the diagnostic accuracy of HRCT, it is worth reiterating the basic point that the sign of mosaic attenuation pattern is nonspecific in that it is the dominant abnormality in three completely different types of diffuse pulmonary disease: small airways disease, occlusive vascular disease, or infiltrative lung disease $[15,94-96]$. In a study of 70 patients in whom the mosaic attenuation pattern was the dominant HRCT abnormality, WORTHY et al. [97] showed that small airways disease and infiltrative lung disease were readily and correctly identified but the mosaic attenuation pattern caused by occlusive vascular disease was frequently misinterpreted. Bronchial abnormalities and the presence of air-trapping on expiratory CT scans are the most useful discriminatory features in identifying small airways disease as the cause of mosaic attenuation. However, the phenomenon of hypoxic bronchodilatation in chronic occlusive vascular disease [98] complicates the diagnostic process. Nevertheless, the differentiation between the three basic causes of a mosaic attenuation pattern is easily made when the clinical and physiological information is taken into account.

Areas of decreased attenuation of the lung parenchyma on HRCT in patients with severe obstructive airways disease due to constrictive bronchiolitis, are sometimes interpreted as "emphysema"; in constrictive bronchiolitis, the pulmonary vessels in affected lung are attenuated, but not distorted, as is the case in centrilobular emphysema. In a study of patients with bronchiectasis, it was assumed that the widespread areas of decreased attenuation on HRCT were caused by emphysema, accounting for the functional gastrapping [99]. However, the "emphysema" seen in that study was not associated with decreased gas diffusing capacity, the functional hallmark of emphysema. Similarly, in nonsmoking asthmatic individuals, areas of decreased attenuation, scored visually on HRCT have been ascribed to emphysema [100, 101]. However, several strands of evidence suggest that the areas of decreased attenuation identified on HRCT in asthmatics [102, 103], particularly on expiratory images, reflect air-trapping due to small airway obstruction, rather than emphysematous lung destruction [104]: in a study of 18 asthmatics and 22 normal controls, Newman et al. [105] showed more extensive areas of low attenuation $(<-900 \mathrm{HU})$ on expiratory images in asthmatics, but this difference was not found on inspiratory images (areas of low attenuation, if they were caused by emphysema, would be expected on inspiratory images). The lack of any significant difference in low attenuation areas of the lung $(<-950 \mathrm{HU})$ in normal through mild-to-severe asthmatic individuals has been confirmed by GEvenoIs et al. [106].

In patients with centrilobular emphysema, the HRCT features of permeative destruction of the lung parenchyma and distortion of the pulmonary vasculature within poorly marginated areas of decreased attenuation are usually sufficiently distinctive to prevent confusion with constrictive obliterative bronchiolitis. However, the differentiation between panacinar emphysema (typified by patients with $\alpha_{1-}$ antitrypsin deficiency) and advanced constrictive obliterative bronchiolitis may be less straightforward on HRCT appearances alone (fig. 11). A recent study that tested the ability of observers to distinguish, on the basis of HRCT appearances alone, between cases of constrictive bronchiolitis, asthma, centrilobular emphysema, panacinar emphysema and normal individuals showed that the first choice diagnosis was correct in 199 of 276 (72\%) observations. Furthermore, agreement on distinguishing between cases of constrictive bronchiolitis and panacinar emphysema (potentially the most challenging diagnostic call on HRCT) was reasonable (kappa 0.63) [107].

The question of the importance, or otherwise, of focal areas of low attenuation consisting of one or more secondary pulmonary lobules has persisted since such "abnormalities" were reported on dynamic expiratory CT in four out of 10 apparently healthy volunteers with normal pulmonary function tests [108]. Such areas of decreased attenuation are not usually present or conspicuous on inspiratory HRCTs of normal individuals [102] and, when identified, need to be distinguished from artefactual areas of low density caused by adjacent ribs (beam hardening artefact). The frequency with which air-trapping is identified on HRCT increases with age as does the extent, which is also influenced by cigarette smoking $[17,109]$. A relatively high prevalence of mosaic pattern has been reported in a study of 14 healthy subjects and 39 asthmatic individuals; a mosaic

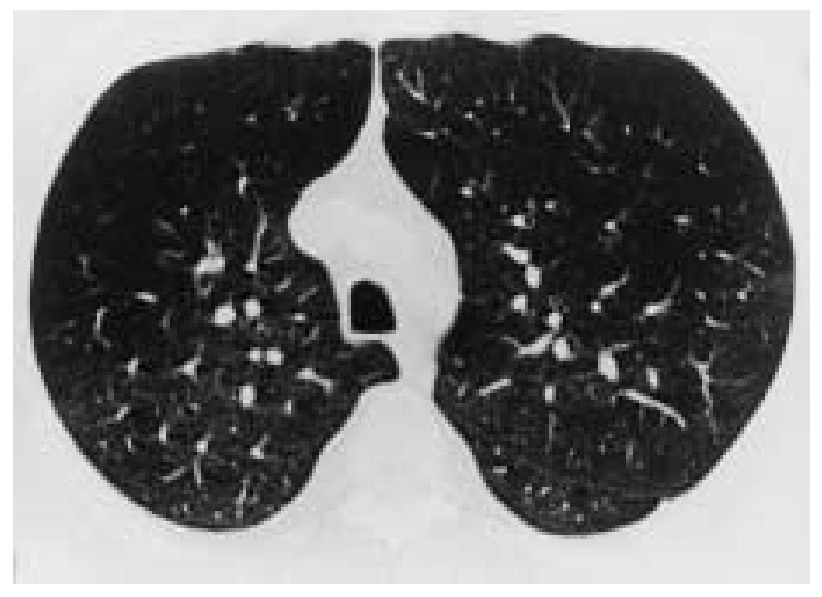

Fig. 11. - Patient with $\alpha_{1}$-antitrypsin deficiency with severe panacinar emphysema in the lower lobes and less advanced emphysema in the upper lobes; the differentiation from constrictive obliterative bronchiolitis is difficult. 
pattern was seen with equal frequency in both groups $(21 \%$ and $18 \%)$ [110]. In addition, trivial extents of airtrapping on expiratory CT occurred with similar frequency in both groups $(54 \%$ and $49 \%)$, whereas severe air-trapping was seen much less frequently in healthy subjects than asthmatics (14\% versus $50 \%)$. The extent of air-trapping did not exceed $25 \%$ of the cross-sectional area of the section in question in any of the healthy subjects. It seems improbable that, as with any other clinical test, a single arbitrary figure can be used to discriminate between normality and disease. For example, the implication of the presence of five secondary pulmonary lobules showing air-trapping on expiratory $\mathrm{CT}$, not previously present on a baseline $\mathrm{CT}$, of a lung transplant patient is clearly very different to the identification of moderately extensive areas of air-trapping in a patient with cigarette smoking induced respiratory bronchiolitis.

\section{Morphological-functional correlations in constrictive bronchiolitis}

In small airways diseases, there is a conceptual void between the information provided by $\mathrm{CT}$ and its correlation with the traditional global information derived from conventional physiological tests; relatively simple correlative studies confirm broadly that the "black lung" component of the mosaic pattern probably reflects small airways disease (rather than emphysema, in the strict pathological sense of the term), but lack of histological studies of "black lung" and limitations of global pulmonary function tests raise the perennial problem of a satisfactory gold standard for a disease as elusive as constrictive bronchiolitis.

There is considerable overlap between the capabilities of image processing techniques that seek, on one hand, to identify and on the other hand, to quantify abnormalities of the lung parenchyma; it is the accurate quantification of abnormal lung that is crucial for the investigation of structure/function relationships. A variety of simple visual scoring systems have been applied to the task of quantifying the CT features of constrictive bronchiolitis, notably the component of decreased lung density of the mosaic attenuation pattern [16, 89, 93]. In a study by LUCIDARME et al. [93], quantification of areas of airtrapping in individuals with chronic airways disease on expiratory $\mathrm{CT}$ was performed using a grid counting system. The intraclass correlation coefficient between two observers was good $(\mathrm{r}=0.86)$, although this may be an overstatement because the coefficient was calculated only for cases in which both observers agreed that air-trapping was present. However, this type of system tends to be labourious and time consuming. Automated objective techniques such as density thresholding [111, 112] are critically dependent upon a clear dichotomy between normal and reduced lung density; while such a difference exists in emphysema, in constrictive bronchiolitis, particularly when admixed with interstitial disease, lung density representing disease is highly heterogeneous and automation of density scoring in this context has proved elusive. Thus, subjective visual scoring systems, sometimes semi-automated, are often favoured for quantitative studies of small airways disease. The "coarseness" of such scoring systems may have a marked effect on observer agreement and thus their effectiveness; using a fine grading system, i.e. the extent of the decreased attenuation component of the mosaic pattern to the nearest $5 \%$, quantitation by observers is relatively inaccurate as judged by the levels of inter- and intra-observer variation; however, a semi-quantitative (coarser) system yields better levels of agreement, at the cost of some loss in discriminatory power associated with the coarser scoring system [113].

In terms of ease of detection, visual quantitation of areas of decreased attenuation is most readily undertaken with expiratory, rather than inspiratory, CT images. Areas of decreased attenuation are identified and scored more confidently on expiratory CT, largely due to a generalized increase in the attenuation of normal lung parenchyma on expiratory scans, enhancing the contrast between normal and affected lung. In a range of conditions characterized by small airways dysfunction, expiratory CT demonstrated areas of decreased attenuation more frequently than inspiratory CT; and the areas of decreased attenuation were of greater extent [113]. The greater extent of decreased attenuation on expiration is partially due to recruitment of new areas of air-trapping on expiration, but there is also a contribution from pre-existing areas of air-trapping seen on inspiratory scans, which necessarily occupy a greater proportion of lung on expiratory scans. Furthermore, observer confidence and agreement is substantially higher on expiratory CT than inspiratory CT in conditions including hypersensitivity pneumonitis, sarcoidosis and asthma [113].

Because the density differences between normal and abnormal areas of lung in patients with small airways disease are sometimes extremely subtle, any method of enhancing the large area low contrast differences are potentially valuable [30]. However, such techniques are unlikely to be applicable to conditions in which a combination of pathological processes coexist resulting in a complex mixture of CT densities and textures. A pragmatic approach is the combination of relatively simple (objective) postprocessing for image feature enhancement and (subjective) visual estimation of the extent of abnormality (this has the advantage that observers can take account of artefacts introduced by the image processing). An example of this approach is the application of MinIP images and similar postprocessing to the quantitation of a mosaic pattern in small airways disease [29, 30].

Several studies have investigated the relationships between the reported signs of constrictive bronchiolitis (areas of decreased attenuation, bronchial abnormalities, and lack of change in cross-sectional area on expiratory CT) and indices of airflow obstruction. The identification of individual CT signs which most strongly predict airflow obstruction in constrictive bronchiolitis is of relevance to the study of other diseases characterized by more complex pathophysio$\operatorname{logy}$ in which there are functional elements of restriction and obstruction. In an early study that 
sought to correlate pulmonary function abnormalities with the extent of CT features of constrictive bronchiolitis, no significant relationships were found except between the forced expiratory volume in one second (FEV1) and the number of bronchopulmonary segments containing dilated subsegmental bronchi [90]. Explanations for the apparent lack of any linkage between structure and function in this study include patient selection; nearly half had CT features of diffuse panbronchiolitis, which is characterized by a mixed restrictive and obstructive pattern on pulmonary function tests [114]. Thus, any correlation between indices of airflow obstruction and the CT features representing pure constrictive bronchiolitis were lost because of the "noise" introduced by the substantial proportion of cases with diffuse panbronchiolitis. Furthermore, expiratory CT scans were not evaluated, and more general functional indices of air-trapping were used rather than specific tests of small airways function such as the maximum expiratory flow rate at $25 \%$ above residual volume (MEFF25\%) [115].

A more recent study examined which of the CT signs of constrictive bronchiolitis was most closely related to indices of airflow obstruction (specifically, expiratory flow rate at low lung volumes) [89]. It was shown that while bronchial wall thickness and global change in cross-sectional area (measured difference in lung area on inspiratory versus expiratory CT) correlated with such tests, the extent of decreased attenuation on expiratory CT correlated most strongly with physiological tests of small airways function and this observation remained robust on multivariate analysis [89]. Although change in global cross-sectional area of the lungs on CT may be predictive of the severity of air-trapping in obliterative bronchiolitis, this relationship is more likely to hold when there is generalized rather than patchy involvement of the small airways. The weak correlation between the change in cross-sectional area of the lungs and the $\mathrm{MEF} 25 \%$ or maximum expiratory flow rate at $50 \%$ above residual volume (MEF50\%) indicates that this feature should not be used as a specific sign of small airways disease. Abnormalities of the larger airways, particularly bronchial wall thickness, predictably result in airflow obstruction in many obstructive lung diseases, including constrictive bronchiolitis. Using bivariate analysis it has been demonstrated that the extent of decreased attenuation is independently associated with a reduction in $\mathrm{MEF} 25 \%$, whereas bronchial wall thickening is independently related to global air-trapping (reflected by the residual volume/total lung capacity (RV/TLC) ratio) [89]. The nature of the link between bronchial and bronchiolar abnormalities is unclear. It has previously been suggested that decreased airflow in the small airways may reduce the efficacy of clearance of secretions in the large airways during coughing, increasing susceptibility to bronchial infection and thus leading to damage [116]. However, given the anatomical continuity of the bronchial tree, it may be that the wall thickening of macroscopic bronchi, visible on thin-section $\mathrm{CT}$, is merely a surrogate for invisible bronchiolar abnormalities; the original insult to the airways having affected both the bronchi and bronchioles equally (fig. 12).

It has traditionally been argued that patients with small airways disease have a relatively preserved total lung carbon dioxide diffusing capacity ( $D \mathrm{~L}, \mathrm{CO})$ in contrast to patients with emphysema [117, 118]. However, GELB and coworkers. [119, 120] have shown that the diffusing capacity does not reliably distinguish between emphysema and small airways disease in patients with severe airflow obstruction particularly when the FEV1 is $<1 \mathrm{~L}$ [121]. Nevertheless, adjusted gas transfer $(\mathrm{KCO})$ is relatively preserved in the majority of patients with severe constrictive bronchiolitis [89, 120] (by contrast to the depression of KCO that characterises emphysema). This is an important observation because the distinction between constrictive bronchiolitis and emphysema (notably the panacinar of $\alpha_{1}$-antitrypsin deficiency) may be difficult on the basis of CT appearances alone [83]. Even when the CT abnormalities are typical of constrictive obliterative bronchiolitis, they may be erroneously interpreted as the findings of emphysema (see earlier section on Accuracy). For these reasons, assimilation of the information supplied by HRCT and adjusted gas transfer provides a powerful means of making the sometimes difficult distinction between emphysema and obliterative bronchiolitis.

\section{Diffuse panbronchiolitis}

An exudative bronchiolitis, typified by diffuse (Japanese) panbronchiolitis, results in another basic HRCT sign of small airways disease, namely the "treein-bud" pattern. Diffuse panbronchiolitis is a sinobronchial disease and was initially thought to be confined to Asian countries but sporadic cases have been reported in every continent [122]. Given the clinical features of cough, sputum, chronic sinusitis and progressive obstructive airways disease, it has been suggested that the inclusive term "sino-bronchial

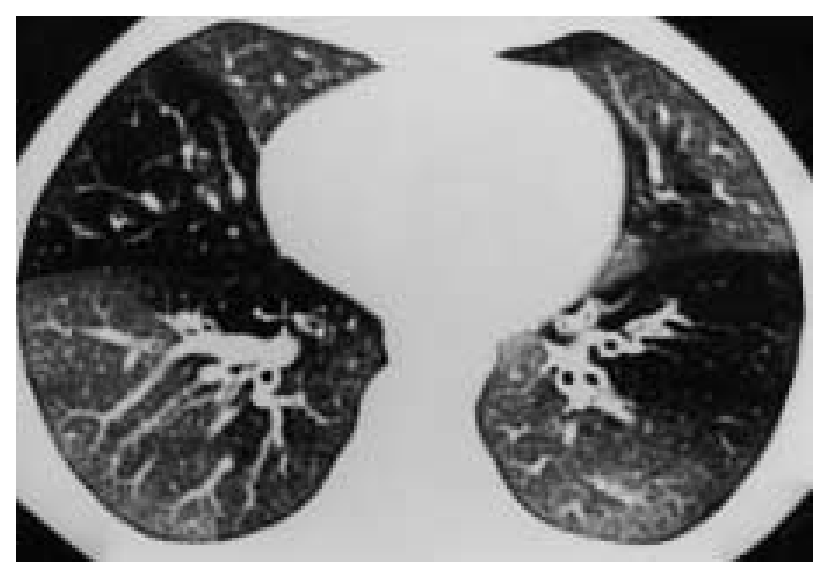

Fig. 12. - Child with a viral lower respiratory tract infection. The CT was obtained during the recovery phase and shows both marked thickening of the segmental and subsegmental bronchi as well as an obvious mosaic attenuation pattern reflecting bronchiolar involvement. 
syndrome" would be more appropriate [123]. However, diffuse panbronchiolitis is relatively unambiguous and well established; most of the definitive histopathological and imaging studies originate from Japan [124-126]. The typical histological features of diffuse panbronchiolitis are chronic inflammatory cell infiltration resulting in bronchiolectasis and striking hyperplasia of lymphoid follicles in the walls of the respiratory bronchioles; profuse foamy macrophages fill the bronchiolar lumen and the immediately adjacent alveoli, although the distal airspaces are not involved. The bronchiolocentric lesions are visible macroscopically as yellow nodules. As the disease progresses, an element of fibrotic bronchiolar constriction supervenes but, in the absence of longitudinal histopathological studies, the extent to which the basic exudative pathology progresses to constrictive bronchiolar obliteration is unclear.

\section{High-resolution computed tomography of diffuse pan- bronchiolitis}

The radiographic pattern in patients with diffuse panbronchiolitis is typically one of numerous small $(<5 \mathrm{~mm})$ ill-defined nodules, such that the radiographic pattern may misleadingly resemble an interstitial, rather than airways-centred, disease. HRCT appearances demonstrate more readily the pathological distribution of disease; there is a nodular pattern and small branching opacities (tree-in-bud pattern [127]) (fig. 13). Bronchioles can be identified in a predominantly centrilobular distribution. It is the florid plugging and thickening of the small airways, with exudate in the immediately surrounding alveoli, that renders visible these otherwise invisible bronchioles. Interestingly, although a mosaic attenuation pattern may be present in some cases, it is not usually a major feature; furthermore, the degree of airtrapping on expiratory $\mathrm{CT}$ is often surprisingly unimpressive. Nevertheless, functional studies have shown that the peripheral zone of the lung is less dense

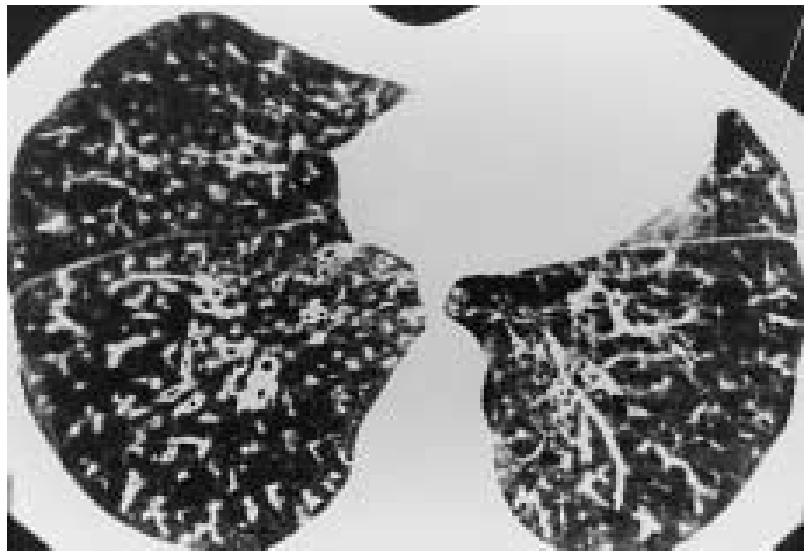

Fig. 13. - Diffuse panbronchiolitis. The peripheral branching structures represent thickened and plugged bronchioles with exudate in the immediately surrounding lung. Mild cylindrical bronchiectasis is an invariable feature of diffuse panbronchiolitis. than normal, presumably because of air-trapping [128].

The HRCT features of diffuse panbronchiolitis, in the appropriate clinical setting, are virtually pathognomonic. However, other conditions may be characterized by a tree-in-bud pattern on HRCT [127, 129] and these are listed in table 3 . In conditions in which tree-in-bud is the dominant feature there is usually abnormality of the macroscopic bronchi, most often manifest as cylindrical bronchiectasis. In conditions in which exudate or secretions are profuse (for example, aspiration pneumonia), there may be accompanying 5-8 mm diameter "acinar nodules" which represent filling of individual acini.

\section{Miscellaneous conditions with small airways involvement}

\section{Extrinsic allergic alveolitis (hypersensitivity pneumo-} nitis)

In this condition, inhalation of organic dusts and deposition in the terminal and respiratory bronchioles cause an inflammatory (or cellular) bronchiolitis of variable severity in susceptible individuals [130]. The potential for varying degrees of involvement of the airways and interstitium, and the coexistence of subacute and more chronic changes, explains the sometimes complex abnormalities found on pulmonary function testing [131]. The HRCT features of subacute extrinsic allergic alveolitis consist of varying proportions of ground-glass opacification, poorly defined centrilobular nodules, and areas of decreased attenuation [132, 133] (fig. 14); these patterns reflect lymphocytic interstitial pneumonitis, peribronchiolar exudate, and bronchiolitis respectively. There is a strong correlation between the extent of the areas of decreased attenuation (a component of the mosaic attenuation pattern) on HRCT and pulmonary function indices of air-trapping $[134,135]$. The airtrapping, graphically shown on expiratory $\mathrm{CT}$, is present in the great majority of patients with subacute disease, and reflects the underlying component of bronchiolitis. Even in patients with chronic fibrotic disease, expiratory CT may show lobular air-trapping amongst the reticular pattern. Some reports have

Table 3. - Conditions characterized by tree-in-bud pattern on high-resolution computed tomography

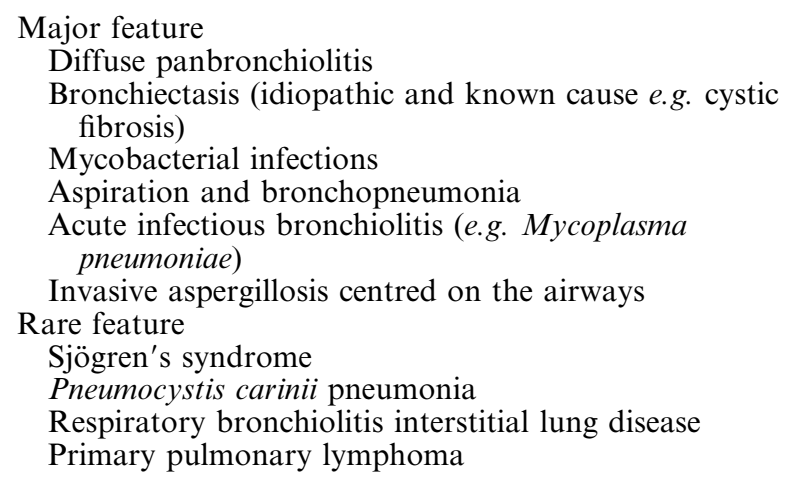




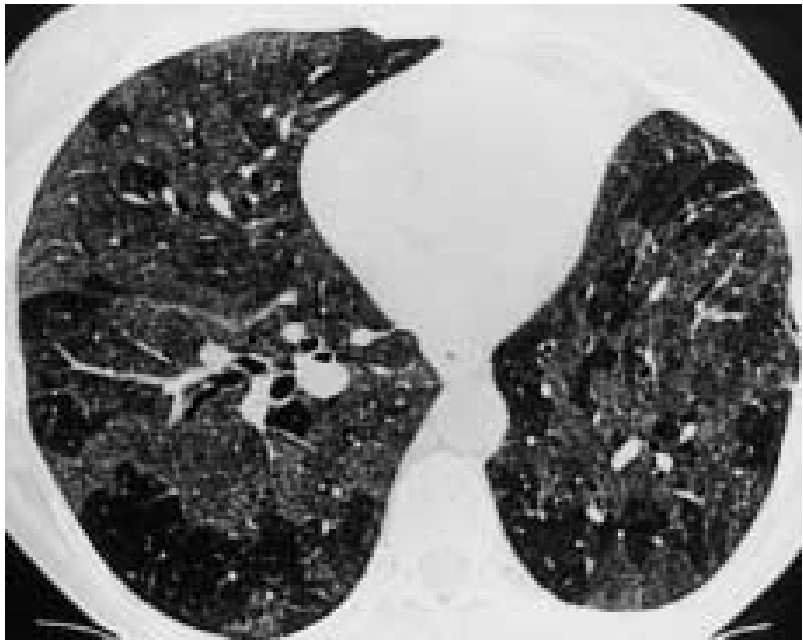

Fig. 14. - Subacute extrinsic allergic alveolitis. On this inspiratory high-resolution computed tomography section through the lower lobes there is a complex combination of patterns comprising: patchy ground-glass opacification, a faint nodular element, and several "spared" secondary pulmonary lobules of decreased attenuation (reflecting the accompanying bronchiolitis). In addition, in the left lower lobe there is distortion of the lung parenchyma and some dilatation of the subsegmental bronchi, reflecting supervening interstitial fibrosis. An expiratory computed tomography section at this level emphasizes the patchy air-trapping.

implicated emphysema as the cause of areas of decreased attenuation in chronic cases of extrinsic allergic alveolitis [133, 136, 137]. The distinction between areas of decreased parenchymal attenuation due to early emphysema, before there is the characteristic permeative destruction and distortion of the pulmonary vasculature, and obliterative bronchiolitis is not always possible on HRCT. Because of the alveolitic and/or fibrotic component in extrinsic allergic alveolitis, a reduction in gas transfer cannot be used to discriminate emphysema from small airways disease [79]. The coexistence of an obliterative bronchiolitis and emphysema as part of the pathological constellation of hypersensitivity pneumonitis are not mutually exclusive. It has been proposed that emphysema may develop secondary to "proximal" obliterative bronchiolitis [133]; against this is the lack of evidence that emphysema is the sequel of other forms of constrictive obliterative bronchiolitis. Another possibility is that, in the absence of significant bronchiolitis, high levels of elastase and release of oxidants, as part of a chronic alveolitis, might be responsible [137]. Although the identification of emphysema in the presence of interstitial fibrosis is controversial [138], it is possible that areas of emphysema occur interspersed among pulmonary fibrosis in chronic cases of hypersensitivity pneumonitis. Nevertheless, in a study of patients with subacute, but not chronic, extrinsic allergic alveolitis, multivariate analysis showed that there was no independent relationship between the extent of decreased attenuation on CT and DL,CO; but there was a relationship with $\mathrm{RV} / \mathrm{TLC}$, which would favour bronchiolitis, rather than emphysema, as the cause of areas of decreased attenuation [134].

\section{Sarcoidosis}

By virtue of their perilymphatic distribution, sarcoid granulomas are concentrated around the airways. Physiological studies suggested that airflow obstruction located at the level of the small airways may be an early feature of sarcoidosis [139, 140]. Supportive evidence, in the form of patchy airtrapping seen on expiratory CT, was first described in three case reports [141] and later confirmed in a larger series [142, 143] (fig. 15). In some cases the airtrapping, thought to reflect bronchiolar obstruction, foreshadows the more typical parenchymal manifestations of sarcoidosis. It seems that this phenomenon is common in patients with sarcoidosis at presentation (demonstrated in 20 of 21 patients in one series [142]). However, the exact prevalence of this phenomenon and its clinical significance, if any, are as yet unknown.

\section{Follicular bronchiolitis}

Follicular bronchiolitis is primarily a histopathological diagnosis and is characterized by hyperplastic lymphoid follicles ranged along bronchioles which are consequently compressed; there is also infiltration of the adjacent bronchiolar walls and interstitium by polyclonal lymphocytes $[144,145]$. The exact relationship between follicular bronchiolitis, lymphocytic interstitial pneumonitis and constrictive obliterative bronchiolitis, particularly in patients with rheumatoid arthrititis in whom these pathologies may coexist, remains controversial [146]. Follicular bronchiolitis is most commonly encountered in patients with rheumatoid arthritis or Sjögren's syndrome, but other associations include a familial form with immunodeficiency [144]. The prognostic implication of follicular bronchiolitis (a diagnosis usually made on the basis of lung biopsy) is uncertain, particularly as it may be identified on a background of an idiopathic interstitial pneumonia in association with a connective

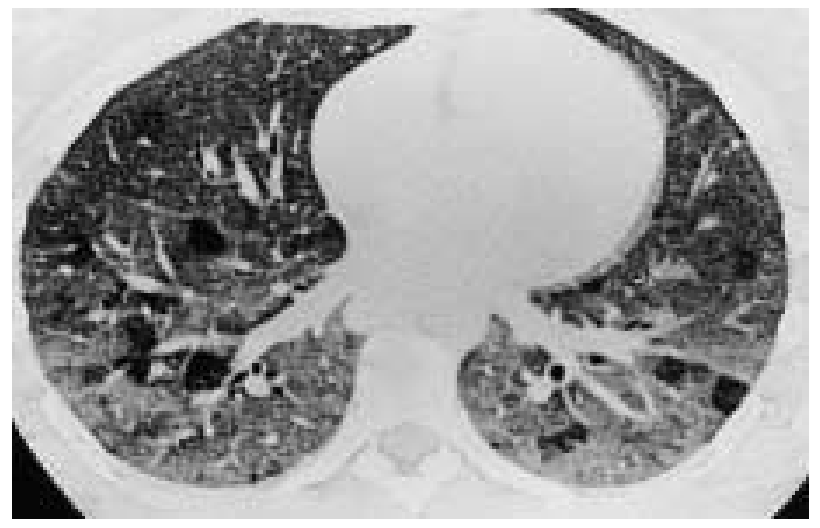

Fig. 15. - Expiratory computed tomography section of a patient with transbronchial biopsy evidence of pulmonary sarcoidosis. The inspiratory high-resolution computed tomography showed a few nodules only, this expiratory section shows the patchy airtrapping at a lobular level, presumed to be caused by bronchiolar compression from adjacent sarcoid granulomata. 
tissue disease. In some individuals, compression of the bronchioles by the hyperplastic follicles results in severe airflow limitation [147]. Peribronchial lymphoid hyperplasia in children (termed follicular bronchitis) may represent an exaggerated immune response to a viral infection, and may result in mild airflow obstruction in the long-term [148].

The plain chest radiograph shows nonspecific small nodular or reticulonodular opacities [145, 149], but may be normal. In an HRCT study of 14 patients (12 with a connective tissue disease) with biopsy proven follicular bronchiolitis, the predominant abnormality was small nodules $(3 \mathrm{~mm}$ diameter, but up to $12 \mathrm{~mm}$ in some cases) [150]. In some cases, the nodules had a predictably centrilobular bronchocentric distribution, such that the HRCT pattern resembled sarcoidosis (fig. 16). Areas of ground-glass opacification probably reflect the more generalized lymphocytic infiltration, present in just over half of the patients [150]. Mild bronchial dilatation with wall thickening occurs in some cases, but whether this is directly related to the presence of follicular bronchiolitis, or is associated with the background autoimmune disease, is unclear.

\section{Micro-carcinoid tumourlets}

Hyperplastic aggregates of neuroendocrine cells cause an extremely unusual form of obliterative bronchiolitis. Diffuse hyperplasia or more focal carcinoid-like tumourlets are associated with fibrosis and scarring of the bronchioles [151-153]. The functional consequences of the resulting constrictive obliterative bronchiolitis may be very severe. On HRCT, there are nodules of varying sizes reminiscent of metastatic disease (although the tumourlets are not malignant in behaviour); close examination of the distribution of the larger nodules shows that they may arise at the carinas of adjoining airways (the typical location of "conventional" carcinoid tumours). The nodules are superimposed on a background mosaic attenuation pattern reflecting the accompanying

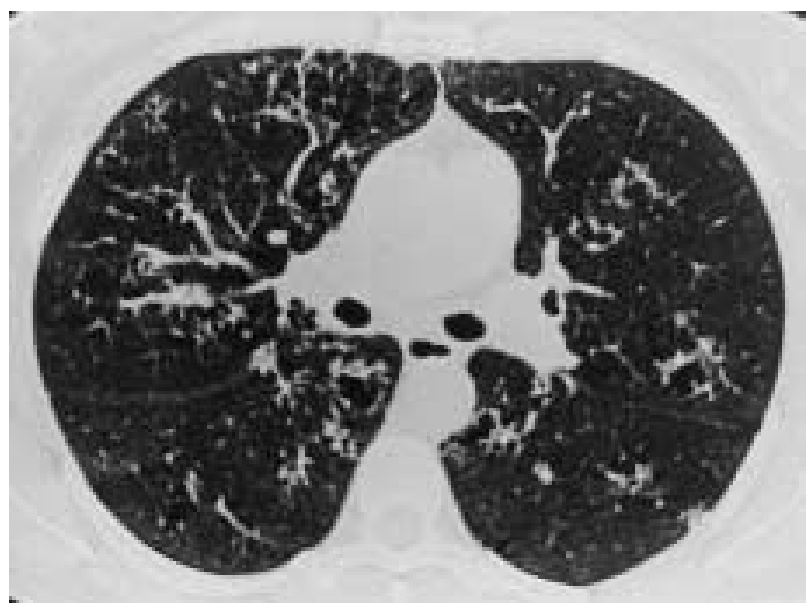

Fig. 16. - Patient with rheumatoid arthritis and biopsy-proven follicular bronchiolitis. There are curious bronchocentric opacities, with some adjacent lung destruction; this distribution of disease superficially resembles sarcoidosis. obliterative bronchiolitis [153] (fig. 17). These two HRCT signs are individually entirely nonspecific but, taken together in the context of a patient with disabling airflow limitation, they are suggestive of this curious and rare condition.

\section{Respiratory bronchiolitis-associated interstitial lung disease}

The concept of damage to the small airways by cigarette smoke is not new. In an early necropsy study of the lungs of young smokers (who died from an unrelated cause), the characteristic pathological features were respiratory bronchiolitis, an abundance of pigmented alveolar macrophages within the lumina of the respiratory bronchioles, and associated mild peribronchiolar interstitial fibrosis [154]. The term respiratory bronchiolitis-associated interstitial lung disease (RB-ILD) has been coined to describe this reasonably distinctive lesion found in cigarette smokers [155]. It seems likely that mild pathological changes of RB-ILD are present in most smokers' lungs, but that very few individuals develop a full clinico-pathological syndrome with symptoms ascribable to RB-ILD. The dominant pathological abnormality is the profusion of intra-alveolar macrophages, such that there is an obvious overlap between the pathological features of RB-ILD and desquamative interstitial pneumonitis (DIP) [156]; this outpouring of macrophages into the airspaces may be regarded as an idiosyncratic reaction to (heavy) cigarette smoke exposure, and results in areas of ground-glass opacification on HRCT [156, 157]. Ancillary HRCT features include poorly defined centrilobular nodules and, rarely, a tree-in-bud pattern [157]. Accompanying interstitial fibrosis is of highly variable severity, but is usually a minor component. However, in one series the features of usual interstitial pneumonia (honeycombing) on HRCT were present in three of 10 patients [158]. Similarly, centrilobular or paraseptal emphysema, when present is usually of surprisingly

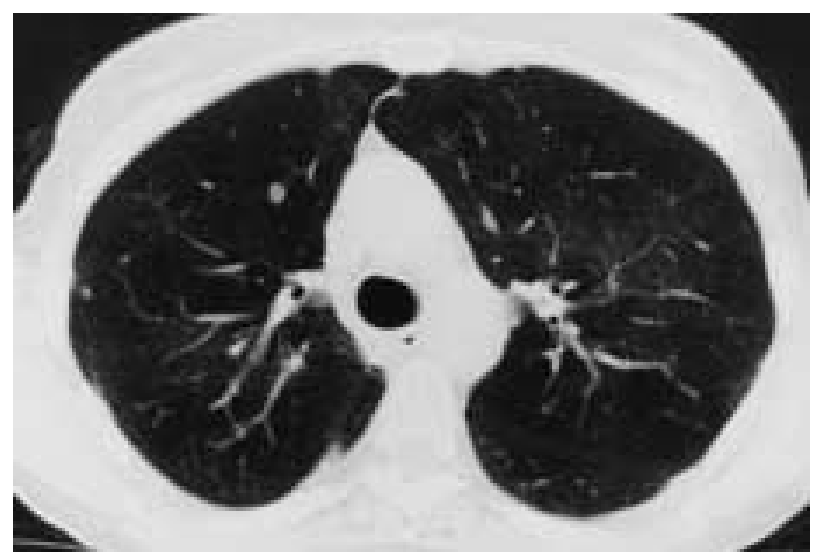

Fig. 17. - Micro-carcinoid tumourlets in a patient with severe obstructive lung disease. Superimposed on the background of mosaic attenuation pattern, there are several nodules ranging in size from a few millimetres to $1 \mathrm{~cm}$ (the carcinoid-like foci, many of which abut and obliterate small airways). 
minor severity. Given the potential for considerably different proportions of each pathological component in a given cigarette smoker $[156,159]$, and the uncertainty about what constitutes "pure" RB-ILD, as opposed to pure respiratory bronchiolitis or pure DIP, it has been suggested that the term "smoking related interstitial lung disease" be used to cover the whole spectrum [158]. Given the considerable variability in the proportions of the individual components in RB-ILD, it is not surprising that there is no predictable correlation between the presence of the pathological entity of RB-ILD and clinical symptoms or functional abnormalities (the latter usually showing a mild restrictive defect with reduced gas transfer) [160].

The radiographic and $\mathrm{CT}$ appearances are nonspecific $[156,161]$. The CT in some biopsy proven cases may be normal [159]. The typical constellation of HRCT features include: patchy ground-glass opacification (most probably reflecting the DIP component) [162,163], poorly defined centrilobular nodules [156], a limited reticular pattern with some thickening of the interlobular septa (probably due to interstitial fibrosis), minor thickening of the macroscopic airways (possibly reflecting chronic bronchitis), and some areas (usually lobular) of decreased attenuation, caused by the respiratory bronchiolitis (fig. 18). Emphysema is generally a minor feature and abnormalities centred on the small airways (i.e. the respiratory bronchiolitis) are not usually obvious; possibly masked by the coexisting patchy interstitial and airspace pathology. To date there are no reports about the utility of expiratory CT in patients with RBILD. Taking together the features listed above, the overall HRCT appearances may be reminiscent of subacute hypersensitivity pneumonitis, and thus knowledge of the patient's smoking history is important in refining the differential diagnosis.

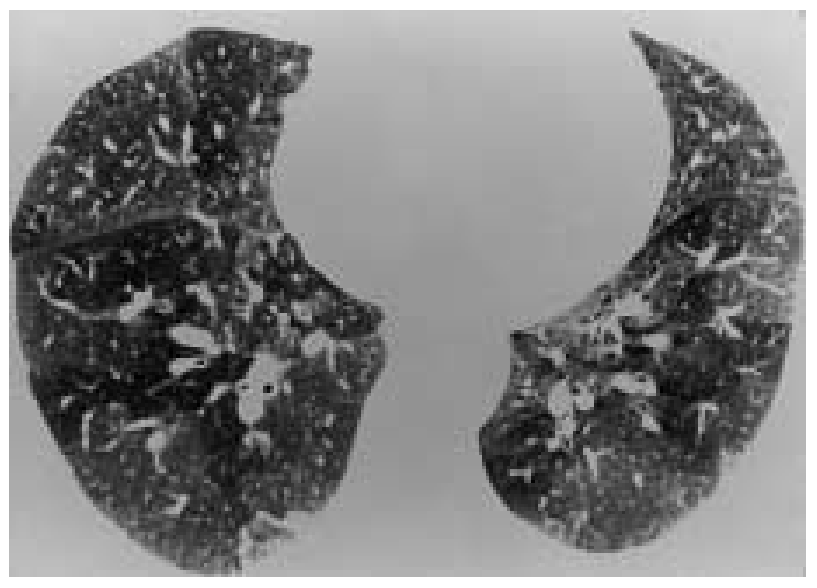

Fig. 18. - Respiratory bronchiolitis: interstitial lung disease. The mosaic attenuation pattern reflects the respiratory bronchiolitis (areas of decreased attenuation) and the desquamative interstitial pneumonitis component (areas of relatively increased attenuation lung parenchyma), i.e. the patchy density differences reflect coexisting interstitial and airways involvement (similar to subacute extrinsic allergic alveolitis).

\section{Conclusion}

HRCT has made progress towards the characterization and detection of a group of diseases which, until relatively recently, had been regarded as being beyond the scope of radiological imaging. From the imaging viewpoint, it seems logical to categorize small airways diseases into those conditions showing indirect signs on HRCT (the mosaic attenuation pattern of constrictive bronchiolitis) and those in which the affected airways are directly visualized (the tree-in-bud sign of exudative bronchiolitis). The strong correlation between the various HRCT signs of bronchiolar diseases and physiological measures of small airways dysfunction has largely confirmed the robustness of these indirect and direct HRCT signs. With the increasing interest in teasing out differences between conditions included under the umbrella of COPD, there is further scope for HRCT to differentiate between the entities that make up this unsatisfactory and arbitrary grouping. The ready availability of a diagnostic test should not allow some caveats to be overlooked: most patients with common diseases that cause airflow limitation do not need an HRCT examination, the cost-effectiveness of HRCT and radiation implications of using HRCT to screen and categorize large populations have not been investigated, generalizable figures for the sensitivity and specificity of HRCT for the detection of "significant" small airways disease are not available and depend to a considerable extent on the type of disease being sought (vide postlung transplant obliterative bronchiolitis).

Despite these provisos, high-resolution computed tomography should be seen as an invaluable diagnostic tool for patients with unexplained obstructive lung disease and as a research tool for characterizing and quantifying morphological features of small airways disease.

\section{References}

1. McAdams HP, Hatabu H, Donnelly LF, Chen Q, Tadamura E, MacFall JR. Novel techniques for MR imaging of pulmonary airspaces. Magnetic Resonance Imaging Clinics of North America 2000; 8: 205-219.

2. Thurlbeck WM. Chronic airflow obstruction. In: Thurlbeck WM, Churg AM, eds. Pathology of the Lung. 2nd edn. New York, Thieme Medical Publishers Inc., 1995; pp. $739-825$.

3. Geddes DM. BOOP and COP. Thorax 1991; 46: $545-$ 547.

4. Sulavik SS. The concept of "organizing pneumonia". Chest 1989; 96: 967-968.

5. Colby TV. Bronchiolar pathology. In: Epler GR, ed. Diseases of the Bronchioles. New York, Raven Press, 1994; pp. $77-100$.

6. Myers JL, Colby TV. Pathologic manifestations of bronchiolitis, constrictive bronchiolitis, cryptogenic organizing pneumonia, and diffuse panbronchiolitis. Clin Chest Med 1993; 14: 611-622.

7. Worthy SA, Müller NL. Small airway diseases. Radiol Clin North Am 1998; 36: 163-173.

8. Hwang JH, Kim TS, Lee KS, et al. Bronchiolitis in 
adults: pathology and imaging. $J$ Comput Assist Tomogr 1997; 21: 913 -919.

9. Webb WR, Gamsu G, Wall SD, Cann CE, Proctor E. CT of a bronchial phantom. Factors affecting appearance and size measurements. Invest Radiol 1984; 19: $394-398$.

10. Seneterre E, Paganin F, Bruel JM, Michel FB, Bousquet J. Measurement of the internal size of bronchi using high resolution computed tomography (HRCT). Eur Respir J 1994; 7: 596-600.

11. Kang EY, Miller RR, Müller NL. Bronchiectasis: comparison of preoperative thin-section $\mathrm{CT}$ and pathologic findings in resected specimens. Radiology 1995; 195: 649-654.

12. Grenier P, Cordeau MP, Beigelman C. High-resolution computed tomography of the airways. $J$ Thorac Imag 1993; 8: 213-229.

13. Bankier AA, Fleischmann D, Mallek $\mathrm{R}$, et al. Bronchial wall thickness: appropriate window settings for thin-section CT and radiologic-anatomic correlation. Radiology 1996; 199: 831 -836.

14. Stern EJ, Frank MS, Godwin JD. Chest computed tomography display preferences. Survey of thoracic radiologists. Invest Radiol 1995; 30: 517-521.

15. Arakawa H, Webb WR, McCowin M, et al. Inhomogeneous lung attenuation at thin-section CT: diagnostic value of expiratory scans. Radiology 1998; 206: $89-94$.

16. Arakawa $\mathrm{H}$, Webb WR. Air trapping on expiratory high-resolution $\mathrm{CT}$ scans in the absence of inspiratory scan abnormalities: correlation with pulmonary function tests and differential diagnosis. AJR 1998; 170: $1349-1353$

17. Verschakelen JA, Scheinbaum K, Bogaert J, Demedts M, Lacquet LL, Baert AL. Expiratory CT in cigarette smokers: correlation between areas of decreased lung attenuation, pulmonary function tests and smoking history. Eur Radiol 1998; 8: 1391-1399.

18. Mitchell AW, Wells AU, Hansell DM. Changes in cross sectional area of the lungs on end expiratory computed tomography in normal individuals. Clin Radiol 1996; 51: 804-806.

19. Kohz P, Stabler A, Beinert T, et al. Reproducibility of quantitative, spirometrically controlled CT. Radiology 1995; 197: 539-542.

20. Beinert T, Behr J, Mehnert F, et al. Spirometrically controlled quantitative CT for assessing diffuse parenchymal lung disease. J Comput Assist Tomogr 1995; 19: 924-931.

21. Robinson TE, Leung AN, Moss RB, Blankenberg FG, al Dabbagh H, Northway WH. Standardized high-resolution $\mathrm{CT}$ of the lung using a spirometertriggered electron beam CT scanner. AJR 1999; 172: $1636-1638$.

22. Franquet T, Stern EJ. Bronchiolar inflammatory diseases: high-resolution CT findings with histologic correlation. Eur Radiol 1999; 9: 1290-1303.

23. Desai SR, Hansell DM. Small airways disease: expiratory computed tomography comes of age. Clin Radiol 1997; 52: 332-337.

24. Stern EJ, Webb WR, Gamsu G. Dynamic quantitative computed tomography. A predictor of pulmonary function in obstructive lung diseases. Invest Radiol 1994; 29: $564-569$.

25. Arakawa H, Webb WR. Expiratory high-resolution CT scan. Radiol Clin North Am 1998; 36: 189-209.

26. Grenier P, Beigelman C. Spiral CT of the bronchial tree. In: Remy-Jardin M, Remy J, eds. Spiral CT of the Chest. Berlin, Springer, 1996; pp. 185-199.

27. Gotway MB, Lee ES, Reddy GP, Golden JA, Webb WR. Low-dose dynamic expiratory thin-section CT of the lungs using a spiral CT scanner. $J$ Thorac Imaging 2000; 15: $168-172$.

28. Remy-Jardin M, Remy J, Gosselin B, Copin MC, Wurtz A, Duhamel A. Sliding thin slab, minimum intensity projection technique in the diagnosis of emphysema: histopathologic-CT correlation. Radiology 1996; 200: 665-671.

29. Bhalla M, Naidich DP, McGuinness G, Gruden JF, Leitman BS, McCauley DI. Diffuse lung disease: assessment with helical CT - preliminary observations of the role of maximum and minimum intensity projection images. Radiology 1996; 200: $341-347$.

30. Yang GZ, Hansell DM. CT image enhancement with wavelet analysis for the detection of small airways disease. IEEE Transactions Medical Imaging 1997; 16: 953-961.

31. Fotheringham $\mathrm{T}$, Chabat $\mathrm{F}$, Hansell DM, et al. A comparison of methods for enhancing the detection of areas of decreased attenuation on CT caused by airways disease. J Comput Assist Tomogr 1999; 23: $385-389$.

32. Rubin GD, Napel S, Leung AN. Volumetric analysis of volumetric data: achieving a paradigm shift. Radiology 1996; 200: 312-317.

33. Becroft DMO. Bronchiolitis obliterans, bronchiectasis, and other sequelae of adenovirus type 21 infection in young children. $J$ Clin Pathol 1971; 24: 72-82.

34. Milner AD, Murray M. Acute bronchiolitis in infancy: treatment and prognosis. Thorax 1989; 44: 1-5.

35. Prabhu MB, Barber D, Cockcroft DW. Bronchiolitis obliterans and Mycoplasma pneumonia. Respir Med 1991; 85: 535-537.

36. Camp M, Mehta JB, Whitson M. Bronchiolitis obliterans and Nocardia asteroides infection of the lung. Chest 1987; 92: 1107-1108.

37. Sato P, Madtes DK, Thorning D, Albert RK. Bronchiolitis obliterans caused by Legionella pneumophila. Chest 1985; 87: 840-842.

38. Chan ED, Kalayanamit T, Lynch DA, et al. Mycoplasma pneumoniae-associated bronchiolitis causing severe restrictive lung disease in adults: report of three cases and literature review. Chest 1999; 115: 1188 1194.

39. Miszkiel KA, Wells AU, Rubens MB, Cole PJ, Hansell DM. Effects of airway infection by Pseudomonas aeruginosa: a computed tomographic study. Thorax 1997; 52: 260-264.

40. Kubo K, Yamazaki Y, Masubuchi T, et al. Pulmonary infection with Mycobacterium avium-intracellulare leads to air trapping distal to the small airways. Am J Respir Crit Care Med 1998; 158: 979-984.

41. Green M, Turton CW. Bronchiolitis and its manifestations. Eur J Respir Dis 1982; 63: 36-42.

42. Lucaya J, Gartner S, Garcia-Pena P, Cobos N, Roca I, Linan S. Spectrum of manifestations of SwyerJames-MacLeod syndrome. J Comput Assist Tomogr 1998; 22: $592-597$.

43. Moore ADA, Godwin JD, Dietrich PA, Verschakelen JA, Henderson WR. Swyer-James syndrome: CT findings in eight patients. AJR 1992; 158: 1211-1215.

44. Marti-Bonmati L, Ruiz Perales F, Catala F, Mata JM, Calonge E. CT findings in Swyer-James syndrome. Radiology 1989; 172: 477-480. 
45. Zhang L, Irion K, da Silva PN, Silva F. Highresolution computed tomography in pediatric patients with postinfectious bronchiolitis obliterans. J Thorac Imaging 1999; 14: 85-89.

46. Douglas WW, Colby TV. Fume-related bronchiolitis obliterans. In: Epler GR, ed. Diseases of the Bronchioles. New York, Raven Press, 1994; pp. 187-213.

47. Douglas WW, Hepper N, Colby TV. Silo filler's disease. Mayo Clin Proc 1989; 64: 291 - 304.

48. Tasaka S, Kanazawa M, Mori M, et al. Long-term course of bronchiectasis and bronchiolitis obliterans as late complication of smoke inhalation. Respiration 1995; 62: 40-42.

49. Wright JL, Cagle P, Churg A, Colby TV, Myers J. Diseases of the small airways. Am Rev Respir Dis 1992; 146: $240-262$.

50. Churg A, Wright JL. Small-airway lesions in patients exposed to non-asbestos mineral dusts. Hum Pathol 1983; 14: $688-693$.

51. Akira M, Yokoyama K, Yamamoto S, et al. Early asbestosis: evaluation with high-resolution CT. Radiology 1991; 178: 409-416.

52. Wells AU, Du Bois RM. Bronchiolitis in association with connective tissue disorders. Clin Chest Med 1993; 14: $655-666$.

53. Geddes DM, Corrin B, Brewerton DA, Davies RJ, Turner-Warwick M. Progressive airway obliteration in adults and its association with rheumatoid arthritis. $Q$ J Med 1977; 46: 427-444.

54. Herzog CA, Miller RR, Hoidal JR. Bronchiolitis and rheumatoid arthritis. Am Rev Respir Dis 1979; 119: $555-560$.

55. Perez T, Remy-Jardin M, Cortet B. Airways involvement in rheumatoid arthritis: clinical, functional, and HRCT findings. Am J Respir Crit Care Med 1998; 157: $1658-1665$.

56. Cortet B, Perez T, Roux N, et al. Pulmonary function tests and high resolution computed tomography of the lungs in patients with rheumatoid arthritis. Ann Rheum Dis 1997; 56: 596-600.

57. Remy-Jardin M, Remy J, Cortet B, Mauri F, Delcambre B. Lung changes in rheumatoid arthritis: CT findings. Radiology 1994; 193: 375-382.

58. Wolfe F, Schurle DR, Lin JJ, et al. Upper and lower airway disease in penicillamine treated patients with rheumatoid arthritis. $J$ Rheumatol 1983; 10: 406-410.

59. Franquet T, Gimenez A, Monill JM, Diaz C, Geli C. Primary Sjogren's syndrome and associated lung disease: CT findings in 50 patients. AJR 1997; 169: 655-658.

60. Cain HC, Noble PW, Matthay RA. Pulmonary manifestations of Sjogren's syndrome. Clin Chest Med 1998; 19: 687-699.

61. Halvorsen RA Jr, DuCret RP, Kuni CC, Olivari MT, Tylen U, Hertz MI. Obliterative bronchiolitis following lung transplantation. Diagnostic utility of aerosol ventilation lung scanning and high resolution CT. Clin Nucl Med 1991; 16: 256-258.

62. Keller CA, Cagle PT, Brown RW, Noon G, Frost AE. Bronchiolitis obliterans in recipients of single, double, and heart-lung transplantation. Chest 1995; 107: $973-$ 980 .

63. Worthy SA, Flint JD, Müller NL. Pulmonary complications after bone marrow transplantation: high-resolution CT and pathologic findings. RadioGraphics 1997; 17: 1359-1371.

64. Paradis I, Yousem S, Griffith B. Airway obstruction and bronchiolitis obliterans after lung transplantation. Clin Chest Med 1993; 14: 751-763.

65. Ko JP, Shepard JA, Sproule MW, et al. CT manifestations of respiratory syncytial virus infection in lung transplant recipients. J Comput Assist Tomogr 2000; 24: $235-241$.

66. Ikonen $\mathrm{T}$, Kivisaari L, Taskinen E, Piilonen A, Harjula ALJ. High-resolution CT in long-term follow-up after lung transplantation. Chest 1997; 111: 370 - 376 .

67. Loubeyre P, Revel D, Delignette A, Loire R, Mornex JF. High-resolution computed tomographic findings associated with histologically diagnosed acute lung rejection in heart-lung transplant recipients. Chest 1995; 107: $132-138$.

68. Loubeyre P, Revel D, Delignette A, et al. Bronchiectasis detected with thin-section CT as a predictor of chronic lung allograft rejection. Radiology 1995; 194 : $213-216$.

69. Leung AN, Fisher K, Valentine V, et al. Bronchiolitis obliterans after lung transplantation: detection using expiratory HRCT. Chest 1998; 113: 365-370.

70. Ikonen T, Kivisaari L, Harjula ALJ, et al. Value of high-resolution computed tomography in routine evaluation of lung transplantation recipients during development of bronchiolitis obliterans syndrome. J Heart Lung Transplant 1996; 15: 587-595.

71. Lee ES, Gotway MB, Reddy GP, Golden JA, Keith FM, Webb WR. Early bronchiolitis obliterans following lung transplantation: accuracy of expiratory thinsection CT for diagnosis. Radiology 2000; 216: $472-$ 477.

72. Lau DM, Siegel MJ, Hildebolt CF, Cohen AH. Bronchiolitis obliterans syndrome: thin-section CT diagnosis of obstructive changes in infants and young children after lung transplantation. Radiology 1998; 208: $783-788$.

73. Morrish WF, Herman SJ, Weisbrod GL, Chamberlain DW. Bronchiolitis obliterans after lung transplantation: findings at chest radiography and high-resolution CT. The Toronto Lung Transplant Group. Radiology 1991; 179: 487-490.

74. Lentz D, Bergin CJ, Berry GJ, Stoehr C, Theodore J. Diagnosis of bronchiolitis obliterans in heart-lung transplantation patients: importance of bronchial dilatation on CT. AJR 1992; 159: 463-467.

75. Kramer MR, Stoehr C, Whang JL, et al. The diagnosis of obliterative bronchiolitis after heart-lung and lung transplantation: low yield of transbronchial lung biopsy. J Heart Lung Transplant 1993; 12: $675-$ 681.

76. Paz HL, Crilley P, Patchefsky A, Schiffman RL, Brodsky I. Bronchiolitis obliterans after autologous bone marrow transplantation. Chest 1992; 101: $775-$ 778 .

77. Breuer R, Lossos IS, Berkman N, Or R. Pulmonary complications of bone marrow transplantation. Respir Med 1993; 87: $571-579$.

78. Madden BP, Hodson ME, Tsang V, Radley-Smith R, Khagani A, Yacoub MY. Intermediate term results of heart-lung transplantation for cystic fibrosis. Lancet 1992; 339: $1583-1587$.

79. Turton CW, Williams G, Green M. Cryptogenic obliterative bronchiolitis in adults. Thorax 1981; 36: $805-810$.

80. Kraft M, Mortenson RL, Colby TV, Newman L, Waldron JA, King TE. Cryptogenic constrictive 
bronchiolitis: a clinicopathologic study. Am Rev Respir Dis 1993; 148: $1093-1101$.

81. Tukiainen P, Poppius H, Taskinen E. Slowly progressive bronchiolitis obliterans: a case report with detailed pulmonary function studies. Eur J Respir Dis 1980; 61: 77-83.

82. Breatnach E, Kerr I. The radiology of cryptogenic obliterative bronchiolitis. Clin Radiol 1982; 33: 657 661.

83. Lynch DA. Imaging of small airways diseases. Clin Chest Med 1993; 14: 623-634.

84. Friedman PJ. Radiology of the airways with emphasis on the small airways. $J$ Thorac Imag 1986; 1: 7-22.

85. Sweatman MC, Millar AB, Strickland B, TurnerWarwick M. Computed tomography in adult obliterative bronchiolitis. Clin Radiol 1990; 41: 116-119.

86. Eber CD, Stark P, Bertozzi P. Bronchiolitis obliterans on high-resolution CT: a pattern of mosaic oligemia. J Comput Assist Tomogr 1993; 17: 853-856.

87. Müller NL, Miller RR. Diseases of the bronchioles: CT and histopathologic findings. Radiology 1995; 196 : $3-12$.

88. Hartman TE, Swensen SJ, Müller NL. Bronchiolar diseases: computed tomography. In: Epler GR, ed. Diseases of the Bronchioles. New York, Raven Press, 1994; pp. $43-58$.

89. Hansell DM, Rubens MB, Padley SPG, Wells AU. Obliterative bronchiolitis: individual CT signs of small airways disease and functional correlation. Radiology 1997; 203: $721-726$.

90. Padley SP, Adler BD, Hansell DM, Müller NL. Bronchiolitis obliterans: high resolution CT findings and correlation with pulmonary function tests. Clin Radiol 1993; 47: 236-240.

91. Stern EJ, Frank MS. Small-airways disease of the lungs: findings at expiratory CT. AJR 1994; 163: $37-$ 41.

92. Guckel C, Wells AU, Taylor DA, Chabat F, Hansell DM. Mechanism of mosaic attenuation of the lungs on computed tomography in induced bronchospasm. J Appl Physiol 1999; 86: $701-708$.

93. Lucidarme O, Coche E, Cluzel P, Mourey-Gerosa I, Howarth N, Grenier P. Expiratory CT scans for chronic airway disease: correlation with pulmonary function test results. AJR 1998; 170: $301-307$.

94. Stern EJ, Swensen SJ, Hartman TE, Frank MS. CT mosaic pattern of lung attenuation: distinguishing different causes. AJR 1995; 165: 813-816.

95. Remy-Jardin M, Remy J, Giraud F, Wattinne L, Gosselin B. Computed tomography (CT) assessment of ground-glass opacity: semiology and significance. J Thorac Imag 1993; 8: 249-264.

96. Austin JHM, Müller NL, Friedman PJ, et al. Glossary of terms for CT of the lungs: recommendations of the nomenclature committee of the Fleischner Society. Radiology 1996; 200: 327-331.

97. Worthy SA, Müller NL, Hartman TE, Swensen SJ, Padley SP, Hansell DM. Mosaic attenuation pattern on thin-section CT scans of the lung: differentiation among infiltrative lung, airway, and vascular diseases as a cause. Radiology 1997; 205: 465-470.

98. Remy-Jardin M, Remy J, Louvegny S, Artaud D, Deschildre F, Duhamel A. Airway changes in chronic pulmonary embolism: CT findings in 33 patients. Radiology 1997; 203: 355-360.

99. Loubeyre P, Paret M, Revel D, Wiesendanger T, Brune J. Thin-section CT detection of emphysema associated with bronchiectasis and correlation with pulmonary function tests. Chest 1996; 109: 360-365.

100. Paganin F, Trussard V, Seneterre E, et al. Chest radiography and high resolution computed tomography of the lungs in asthma. Am Rev Respir Dis 1992; 146: $1084-1087$.

101. Paganin F, Seneterre E, Chanez P, et al. Computed tomography of the lungs in asthma: influence of disease severity and etiology. Am J Respir Crit Care Med 1996; 153: 110-114.

102. Grenier P, Mourey-Gerosa I, Benali K, et al. Abnormalities of the airways and lung parenchyma in asthmatics: CT observations in 50 patients and interand intra-observer variability. Eur Radiol 1996; 6: $199-206$.

103. Laurent F, Latrabe V, Raherison C, Marthan R, Tunon-de-Lara JM. Functional significance of air trapping detected in moderate asthma. Europ Radiol 2000; 10: $1404-1410$.

104. King GG, Müller NL, Pare PD. Evaluation of airways in obstructive pulmonary disease using high-resolution computed tomography. Am J Respir Crit Care Med 1999; 159: $992-1004$.

105. Newman KB, Lynch DA, Newman LS, Ellegood D, Newell JD Jr. Quantitative computed tomography detects air trapping due to asthma. Chest 1994; 106 : $105-109$.

106. Gevenois PA, Scillia P, de MV, Michils A, De VP, Yernault JC. The effects of age, sex, lung size, and hyperinflation on CT lung densitometry. AJR 1996; 167: $1169-1173$.

107. Copley SJ, Well AU, Müller NL, et al. The discriminatory value of high resolution $\mathrm{CT}$ in obstructive lung disease. Br J Radiol 2000; 73: Suppl. 12.

108. Webb WR, Stern EJ, Kanth N, Gamsu G. Dynamic pulmonary CT: findings in healthy adult men. Radiology 1993; 186: 117-124.

109. Lee KW, Chung SY, Yang I, Lee Y, Ko EY, Park MJ. Correlation of aging and smoking with air trapping at thin-section CT of the lung in asymptomatic subjects. Radiology 2000; 214: 831-836.

110. Park CS, Müller NL, Worthy SA, Kim JS, Awadh N, Fitzgerald M. Airway obstruction in asthmatic and healthy individuals: inspiratory and expiratory thinsection CT findings. Radiology 1997; 203: 361-367.

111. Adams H, Bernard MS, McConnochie K. An appraisal of CT pulmonary density mapping in normal subjects. Clin Radiol 1991; 43: $238-242$.

112. Kinsella M, Müller NL, Abboud RT, Morrison NJ, DyBuncio A. Quantitation of emphysema by computed tomography using a "density mask" program and correlation with pulmonary function tests. Chest 1990; 97: $315-321$.

113. Ng CS, Desai SR, Rubens MB, Padley SPG, Wells AU, Hansell DM. Visual quantitation and observer variation of signs of small airways disease at inspiratory and expiratory CT. $J$ Thorac Imaging 1999; 14: 279-285.

114. King TE Jr. Overview of bronchiolitis. Clin Chest Med 1993; 14: $607-610$.

115. McFadden ER, Linden RA. A reduction in maximal end-expiratory flow rate. A spirographic manifestation of small airway disease. Am J Med 1972; 52: $725-$ 737.

116. Hansell DM, Wells AU, Rubens MB, Cole PJ. Bronchiectasis: functional significance of areas of 
decreased attenuation at expiratory CT. Radiology 1994; 193: 369-374.

117. Gelb AF, Zamel N. Simplified diagnosis of smallairway obstruction. $N$ Engl J Med 1973; 288: $395-$ 398.

118. Gelb AF, Gold WM, Wright RR, Bruch HR, Nadel JA. Physiologic diagnosis of subclinical emphysema. Am Rev Respir Dis 1973; 107: 50-63.

119. Gelb AF, Hogg JC, Müller NL, et al. Contribution of emphysema and small airways in COPD. Chest 1996; 109: $353-359$.

120. Gelb AF, Zamel N, Hogg JC, Müller NL, Schein MJ. Pseudophysiologic emphysema resulting from severe small-airways disease. Am J Respir Crit Care Med 1998; 158: $815-819$.

121. Gelb AF, Schein M, Kuei J, et al. Limited contribution of emphysema in advanced chronic obstructive pulmonary disease. Am Rev Respir Dis 1993; 147: $1157-1161$

122. Fitzgerald JE, King TE Jr, Lynch DA, Tuder RM, Schwarz MI. Diffuse panbronchiolitis in the United States. Am J Respir Crit Care Med 1996; 154: $497-$ 503.

123. Koyama H, Geddes DM. Erythromycin and diffuse panbronchiolitis. Thorax 1997; 52: 915-918.

124. Nishimura K, Kitaichi M, Izumi T, Itoh H. Diffuse panbronchiolitis: correlation of high-resolution CT and pathologic findings. Radiology 1992; 184: 779785.

125. Homma H, Yamanaka A, Shinichi T, et al. Diffuse panbronchiolitis: a disease of the transitional zone of the lung. Chest 1983; 83: 63-69.

126. Akira M, Higashihara S, Sakatani M, Hara H. Diffuse panbronchiolitis: follow-up CT examination. Radiology 1993; 189: 559-562.

127. Collins J, Blankenbaker D, Stern EJ. CT patterns of bronchiolar disease: what is "tree-in-bud"? AJR 1998; 171: $365-370$.

128. Murata $\mathrm{K}$, Itoh $\mathrm{H}$, Senda $\mathrm{M}$, et al. Stratified impairment of pulmonary ventilation in "diffuse panbronchiolitis": PET and CT studies. J Comput Assist Tomogr 1989; 13: 48-53.

129. Aquino SL, Gamsu G, Webb WR, Kee ST. Tree-inbud pattern: frequency and significance on thin section CT. J Comput Assist Tomogr 1996; 20: 594-599.

130. Selman-Lama M, Perez-Padilla R. Airflow obstruction and airway lesions in hypersensitivity pneumonitis. Clin Chest Med 1993; 14: 699-714.

131. Warren CP, Tse KS, Cherniack RM. Mechanical properties of the lung in extrinsic allergic alveolitis. Thorax 1978; 33: 315-321.

132. Silver SF, Müller NL, Miller RR, Lefcoe MS. Hypersensitivity pneumonitis: Evaluation with CT. Radiology 1989; 173: $441-445$.

133. Remy-Jardin M, Remy J, Wallaert B, Müller NL. Subacute and chronic bird breeder hypersensitivity pneumonitis: sequential evaluation with $\mathrm{CT}$ and correlation with lung function tests and bronchoalveolar lavage. Radiology 1993; 189: 111-118.

134. Hansell DM, Wells AU, Padley SPG, Müller NL. Hypersensitivity pneumonitis: correlation of individual CT patterns with functional abnormalities. Radiology 1996; 199: 123-128.

135. Small JH, Flower CDR, Traill ZC, et al. Air-trapping in extrinsic allergic alveolitis on CT. Clin Radiol 1996; 51: $684-688$.

136. Erkinjuntti-Pekkanen R, Rytkonen H, Kokkarinen JI,
Tukiainen HO, Partanen K, Terho EO. Long-term risk of emphysema in patients with farmer's lung and matched control farmers. Am J Respir Crit Care Med 1998; 158: $662-665$.

137. Lalancette M, Carrier G, Laviolette M, et al. Farmer's lung. Long-term outcome and lack of predictive value of bronchoalveolar lavage fibrosing factors. Am Rev Respir Dis 1993; 148: 216-221.

138. Snider GL. Pathogenesis and terminology of emphysema. Am J Respir Crit Care Med 1994; 149: $1382-$ 1383.

139. Kaneko K, Sharma OP. Airway obstruction in pulmonary sarcoidosis. Bull Eur Physiopathol Respir 1977; 13: $231-240$.

140. Levinson RS, Metzger LF, Stanley NN, et al. Airway function in sarcoidosis. Am J Med 1977; 62: 51-59.

141. Gleeson FV, Traill ZC, Hansell DM. Expiratory CT evidence of small airways obstruction in sarcoidosis. AJR 1996; 166: 1052 - 1054

142. Davies CWH, Tasker AD, Padley SPG, Davies RJO, Gleeson FV. Air trapping in sarcoidosis on computed tomography: correlation with lung function. Clin Radiol 2000; 55: 217-221.

143. Hansell DM, Milne DG, Wilsher ML, Wells AU. Pulmonary sarcoidosis: morphologic associations of airflow obstruction at thin-section CT. Radiology 1998; 209: 697-704.

144. Yousem SA, Colby TV, Carrington CB. Follicular bronchitis/bronchiolitis. Hum Pathol 1985; 16: 700 706 .

145. Fortoul TI, Cano-Valle F, Oliva E, et al. Follicular bronchiolitis in association with connective tissue diseases. Lung 1985; 163: 305-314.

146. Hayakawa $\mathrm{H}$, Sato A, Imokawa S, Toyoshima M, Chida K, Iwata M. Bronchiolar disease in rheumatoid arthritis. Am J Respir Crit Care Med 1996; 154: 1531 1536.

147. Oh YW, Effmann EL, Redding GJ, Godwin JD. Follicular hyperplasia of bronchus-associated lymphoid tissue causing severe air trapping. AJR 1999; 172: $745-747$.

148. Bramson RT, Cleveland R, Blickman JG, Kinane TB. Radiographic appearance of follicular bronchitis in children. AJR 1996; 166: 1447-1450.

149. Yousem SA, Colby TV, Carrington CB. Lung biopsy in rheumatoid arthritis. Am Rev Respir Dis 1985; 131: $770-777$.

150. Howling SJ, Hansell DM, Wells AU, Nicholson AG, Flint JD, Müller NL. Follicular bronchiolitis: thinsection CT and histologic findings. Radiology 1999; 212: $637-642$

151. Aguayo SM, Miller YE, Waldron JA, Bogin RM, Sunday ME, Staton GW. Idiopathic diffuse hyperplasia of pulmonary neuroendocrine cells and airways disease. N Engl J Med 1992; 327: 1285-1288.

152. Brown MJ, English J, Müller NL. Bronchiolitis obliterans due to neuroendocrine hyperplasia: high resolution CT - pathologic correlation. AJR 1997; 168: $1561-1562$.

153. Sheerin N, Harrison NK, Sheppard MN, Hansell DM, Yacoub M, Clark TJ. Obliterative bronchiolitis caused by multiple tumourlets and microcarcinoids successfully treated by single lung transplantation. Thorax 1995; 50: 207-209.

154. Niewoehner DE, Kleinerman J, Rice DB. Pathologic changes in the peripheral airways of young cigarette smokers. N Engl J Med 1974; 291: 775-777. 
155. King TE. Respiratory bronchiolitis-associated interstitial lung disease. Clin Chest Med 1993; 14: $693-$ 698.

156. Heyneman LE, Ward S, Lynch DA, Remy-Jardin M, Johkoh T, Müller NL. Respiratory bronchiolitis, respiratory bronchiolitis-associated interstitial lung disease, and desquamative interstitial pneumonia: different entities or part of the spectrum of the same disease process? AJR 1999; 173: 1617-1622.

157. Essadki O, Chartrand-Lefebvre C, Briere J, Grenier P. Respiratory bronchiolitis: radiographic and CT findings in a pathologically proven case. Eur Radiol 1998; 8: $1674-1676$.

158. Moon J, Du Bois RM, Colby TV, Hansell DM, Nicholson AG. Clinical significance of respiratory bronchiolitis on open lung biopsy and its relationship to smoking related interstitial lung disease. Thorax 1999; 54: 1009-1014.

159. Hartman TE, Tazelaar HD, Swensen SJ, Müller NL. Cigarette smoking: CT and pathologic findings of associated pulmonary diseases. RadioGraphics 1997; 17: $377-390$.

160. Myers JL, Veal CF, Shin MS, Katzenstein ALA. Respiratory bronchiolitis causing interstitial lung disease: a clinicopathologic study of six cases. $\mathrm{Am}$ Rev Respir Dis 1987; 135: 880-884.

161. Holt RM, Schmidt RA, Godwin JD, Raghu G. High resolution $\mathrm{CT}$ in respiratory bronchiolitis-associated interstitial lung disease. J Comput Assist Tomogr 1993; 17: $46-50$.

162. Remy-Jardin M, Remy J, Boulenguez C, Sobaszek A, Edme JL, Furon D. Morphologic effects of cigarette smoking on airways and pulmonary parenchyma in healthy adult volunteers: CT evaluation and correlation with pulmonary function tests. Radiology 1993; 186: $107-115$.

163. Remy-Jardin M, Remy J, Gosselin B, Becette V, Edme JL. Lung parenchymal changes secondary to cigarette smoking: pathologic-CT correlations. Radiology 1993; 186: $643-651$. 